\title{
Pickering emulsions stabilized by carboxylated nanodiamonds over a broad $\mathrm{pH}$ range
}

\author{
Zhiwei Huang a , Izabela Jurewicz ${ }^{\text {a }}$, Edgar Muñoz ${ }^{\mathrm{b}}$, Rosa Garriga ${ }^{\mathrm{c}}$, Joseph L. Keddie ${ }^{\text {a, }}{ }^{*}$ \\ ${ }^{a}$ Department of Physics, Faculty of Engineering and Physical Sciences, University of Surrey, \\ Guildford, GU2 7XH, UK \\ ${ }^{\mathrm{b}}$ Instituto de Carboquímica ICB-CSIC, Miguel Luesma Castán 4, 50018 Zaragoza, Spain \\ c Departamento de Química Física, Universidad de Zaragoza, 50009 Zaragoza, Spain \\ *Corresponding author. Tel: +44 1483 686803. E-mail: j.keddie@surrey.ac.uk (Joseph L. Keddie)
}

\begin{abstract}
Hypothesis

Surfactants in emulsions sometimes do not provide adequate stability against coalescence, whereas Pickering emulsions often offer greater stability. In a search for stabilizers offering biocompatibility, we hypothesized that carboxylated nanodiamonds (ND) would impart stability to Pickering emulsions.
\end{abstract}

\section{Experiments}

We successfully prepared Pickering emulsions of sunflower oil in water via two different methods: membrane emulsification and probe sonication. The first method was only possible when the $\mathrm{pH}$ of the aqueous ND suspension was $\leq 4$.

\section{Findings}

Pendant-drop tensiometry confirmed that carboxylated ND is adsorbed at the oil/water interface, with a greater decrease in interfacial tension found with increasing ND concentrations in the aqueous phase. The carboxylated ND become more hydrophilic with increasing $\mathrm{pH}$, according to three-phase contact angle analysis, because of deprotonation of the carboxylic acid groups. Membrane emulsification yielded larger (about $30 \mu \mathrm{m}$ ) oil droplets, probe sonication produced smaller (sub- $\mu \mathrm{m})$ oil droplets. The Pickering emulsions show high stability against mechanical vibration and long-term storage for one year. They remain stable against coalescence across a wide range of $\mathrm{pH}$ values. Sonicated emulsions show stability against creaming. In this first-ever systematic study of carboxylated ND-stabilized Pickering emulsions, we demonstrate a promising application in the delivery of $\beta$-carotene, as a model active ingredient.

Keywords: nanodiamond; Pickering emulsion; membrane emulsification; saponification 


\section{Introduction}

Conventional emulsions are typically stabilized by low molecular weight surfactants or by amphiphilic macromolecules, such as proteins and polysaccharides (with a size typically smaller than $5 \mathrm{~nm}$ ). In the early 1900s, Ramsden and Pickering reported an alternative way to stabilize emulsions by using small solid particles (ranging in size from $5 \mathrm{~nm}$ to several $\mu \mathrm{m}$ ), leading to the name of Pickering emulsions.[1,2] There is already a tremendous amount of fundamental academic research work about the preparation methods and thermodynamics of Pickering emulsions.[3,4] Compared with the classical surfactant-stabilized emulsions, Pickering emulsions show attractive qualities in their long-term stability against coalescence. Researchers have reported instances where conventional surfactants cause tissue irritation or even damage to biological cells, $[5,6]$ which is driving further interest in Pickering emulsions.

The versatility of stabilising particles for Pickering emulsions and their potential ability to encapsulate and controllably release cargo with high internal payload capacity make them very attractive for the delivery of active ingredients in personal care products and pharmaceuticals. However, not all particles are suitable for applications where they will be used dermally, orally or internally. Though inorganic particles, such as $\mathrm{SiO}_{2}$ and $\mathrm{TiO}_{2},[7,8]$ and organic particles, including polymers such as poly(lactic-co-glycolic acid) or PLGA,[9] poly(lactide)-blockpoly(ethylene glycol) (PLA-b-PEG) or poly(caprolactone)-block- poly(ethylene glycol) (PCLb-PEG)[10] have been proven to be good candidates for preparing Pickering emulsions for biomedical uses, the extent of biodegradability and biocompatibility of the particles in the human body is of serious concern.

To address these concerns, naturally-occurring (food-grade) particles, such as cellulose, starch, or chitosan have been used as emulsifiers instead.[11] However, the choices for this kind of food-grade particle are limited because most types of particles do not remain insoluble and intact in both the water and oil phases over the lifetime of an emulsion system. Polysaccharide-based materials may be deformed in the water phase, and many proteins are even water-soluble. Though there are some insoluble food-grade particles which could possibly be used to fabricate Pickering emulsions, such as cellulose [12] and chitin,[13] their particle size and size distribution are difficult to control in the particle synthesis. Furthermore, the wettability of unmodified food-grade particles could be inadequate for emulsification. For instance, polysaccharide materials are normally too hydrophilic to be an emulsifier if they are not properly modified. Extensive processing requirements to prepare food-grade particlestabilized Pickering emulsions will greatly increase the cost of commercial applications.[14] 
The biocompatibility, stability and facile surface modification of carbon-based particles make them an attractive choice for fabricating Pickering emulsions.[15] Graphene oxide (GO) has a unique structure of carboxylic acid at the edges and phenol hydroxyl and epoxide groups mainly on the basal plane. Exploiting this chemical structure, Kim and co-workers [16] were the first to use GO as a Pickering stabilizer. They defined GO as amphiphilic, whereas most researchers regard it as hydrophilic due to its good dispersibility in water. They also found that the wettability of GO changed with various $\mathrm{pH}$ levels of the liquid because of the protonation and deprotonation of the carboxylic acid group. Hence, they fabricated a $\mathrm{pH}$-dependent and pH-responsive Pickering emulsion using GO. The Pickering emulsion showed good stability in a pH 2 environment, while all GO was ejected into water phase when the $\mathrm{pH}$ was adjusted to 10 . Since then, a large amount of research using exfoliated graphene $[17,18]$ and GO $[19,20]$ to stabilize Pickering emulsions and to synthesize polymer nanocomposites [21] has been reported.

Carbon black (CB) is another carboxylic acid-terminated functional particle that has been used to fabricate $\mathrm{pH}$-responsive Pickering emulsions.[22,23] However, there is a high density of carboxylic acid groups on the surface of carboxylic acid-terminated CB particles, making them too hydrophilic to stabilize Pickering emulsions. Saha et al.[23] fabricated CB-stabilized Pickering emulsions by adding acid or salt to the dispersion to impart some partial hydrophobicity. Their emulsions were more stable in an acid environment due to the protonation of carboxylic acid groups.

Nanodiamonds (ND) have been reported to exhibit low toxicity[24,25] and the highest biocompatibility compared to other carbon nanomaterials such as $\mathrm{CB}$, carbon nanotubes (CNTs), carbon nanohorns, carbon nanoplatelets, and GO,[26,27] thereby offering obvious advantages in applications in the biomedical area. Raw detonation ND materials consist of diamond cores, typically $5>\mathrm{nm}$ in size, coated with disordered sp3 carbon and graphitic nanostructures having a variety of surface functional groups, primarily containing oxygen (i.e. carboxyl, hydroxyl, ether and keto groups). The availability of purified and de-agglomerated, single-digit detonation ND opens new and exciting opportunities for applications in colloidal technology.[28] Also, carboxylic functionalization of ND allows the covalent bonding or adsorption of a variety of moieties of interest in materials science and biomedicine, as well as superior drug and biomaterial loading capabilities.[29-31] 
Much is still to be learned about the suitability of ND for Pickering emulsions. In an early study, Maas et al. [32] reported using ND to produce a colloidosome structure, which they called a diamondosome, with a high shell stability. The authors mainly validated the synergistic effect of the same sign of charges of ND and oil-soluble surfactants in fabricating stable ND capsules by using interfacial shear rheology. Notably, Pickering oil-in-water emulsions have been created using hydroxylated detonation ND (aggregate size of $30 \mathrm{~nm}$ ) using a sonication method.[33] Rheological analysis of concentrated emulsions showed that interactions between the ND stabilizers provided behaviour that combined that of colloidal gels and conventional surfactant-stabilized emulsions. There is still an open area and a clear need for a systematic study of ND-stabilized Pickering emulsions, taking into account the effects of $\mathrm{pH}$ and salt addition as well as their loading capabilities, which are of key importance for their application prospects in the biomedical area.

Although there have already been several successful attempts to use ND for drug delivery,[34-36] in nearly all of these examples, researchers attached the drugs to the surface of the ND. When the drugs are exposed to physiological environments, they may cause side effects to the human body or drug failure. However, if ND can be used to stabilize drug molecules (or other active ingredients) within Pickering emulsions, those problems could be avoided, and some other advantages, including high efficiency, colloidal stability, controlled release, and delivery of hydrophobic drugs etc., could be realized.

Sonication is a commonly-used method to prepare Pickering emulsions. A recentlyemerging method is membrane emulsification [37], which offers the benefits of low shearstresses, low energy input, and an ability to upscale. Membrane emulsification has never previously been used with ND as the Pickering stabilizer, but it is our focus here.

In this work, we report the first demonstration of carboxylated ND as a Pickering emulsifier. (For brevity, we will not hereafter always use the adjective "carboxylated", as our experiments only used this type of ND.) Carboxylic functionalization provides greater ND colloidal stability when dispersed in polar solvents [38-40] as well as enhanced ND biocompatibility, which are of great importance for their applications in biomedicine[41]. We investigated the effect of $\mathrm{pH}$ and dissolved ions on the mechanical and storage stability of the emulsions. We have also explored whether an active ingredient ( $\beta$-carotene) could be carried in the oil phase of a model formulation. 


\section{Experimental details}

\subsection{Materials}

Monodispersed, single-digit, carboxylated ND synthesized by the detonation technique (nominally $5 \mathrm{~nm}$ diameter according to the supplier, with a concentration of $10 \mathrm{mg} / \mathrm{mL}$ in water) were used as-received from Sigma-Aldrich. Pure sunflower oil (Flora $@$, Princes Ltd, UK) was used without purification as the oil phase to prepare emulsions. Polyethylene glycol sorbitan monolaurate (Tween 20, product number P1379, Sigma-Aldrich) was used in comparative emulsions as a surfactant. Buffer solutions of $\mathrm{pH} 1.5$ (containing potassium tetroxalate) and $\mathrm{pH} 12$ (containing $\mathrm{Ca}(\mathrm{OH})_{2}$ from Cole-Parmer) were used to adjust the $\mathrm{pH}$ of the water phase during emulsification. Buffer tablets $\mathrm{pH} 4$ (phthalate), $\mathrm{pH} 7$ (phosphate), $\mathrm{pH} 9$ (borate) all obtained from Fisher Scientific, $\mathrm{HCl}$ and $\mathrm{NaOH}$ solutions, $\mathrm{CaCl}_{2}$ and $\mathrm{NaCl}$ powders (all obtained from Sigma-Aldrich) were used in other experiments, described hereafter. $\beta$-carotene (synthetic, $\geqslant 93 \%$, Sigma-Aldrich) was used as a model active ingredient to be carried in oil phase. Deionized (DI) water $(18.2 \mathrm{M} \Omega \cdot \mathrm{cm}$, Elga DI water system) was used in all experiments reported here.

\subsection{Preparation of ND-stabilized Pickering emulsions}

Two methods were developed to prepare ND-stabilized Pickering emulsions. The first method was membrane emulsification [37,42] using a commercial system (LDC 1, Micropore Technologies, Redcar, UK). In this method, oil was injected through a membrane (stainless steel with $5 \mu \mathrm{m}$ pores) at a constant rate into water while stirring the aqueous phase at a fixed speed controlled by a DC Power Supply (model 72-2605, Tenma). A schematic diagram and the mechanism of membrane emulsification is shown in the Supplementary Materials (Fig. S1). The steel membrane (Micropore Technologies) was coated to make it hydrophilic, such that the oil phase did not spread and wet it during emulsification. In a preliminary experiment, the influence of the injection rate on the emulsion size distribution was determined when using Tween 20 as the emulsifier.[43] Results are given in Fig. S2 (Supplementary Materials), from where it is concluded that a lower injection rate renders a more monodispersed emulsion. Therefore, a rate of $40 \mu \mathrm{L} / \mathrm{min}$ was used subsequently for the preparation of ND stabilized Pickering emulsions.

$3 \mathrm{~mL}$ of sunflower oil was injected by a springe pump (1002X, ProSense BV) into a chamber containing $27 \mathrm{~mL}$ of water phase consisting of the ND dispersion in buffers of different $\mathrm{pH}$ values. The emulsion was stirred by a paddle stirrer at a speed of $900 \mathrm{rpm}$. As is 
shown in Fig. S1a, when oil passes through the membrane, the ND particles absorb spontaneously at the interface of oil and water, thereby reducing the interfacial tension of the oil droplets. At the same time, the water flow imposes a shear force on the oil droplets because of the continuous stirring, as is shown in Fig. S1b. With the growth of the size of the oil droplets, the torque force will increase at the same time, until it exceeds the projection of the capillary moment, onto the axis of the rolling drop.[44] Then, the oil droplets are detached into the aqueous phase, and stable Pickering emulsion droplets are created.

The second method to prepare Pickering emulsions was probe sonication emulsification using a probe sonifier (Branson Sonifier 150). $0.5 \mathrm{mg} / \mathrm{mL}$ ND dispersions in buffers of a range of $\mathrm{pH}$ values $(2,4,7,10$ and 12$)$, and also in the presence of salts $\left(1 \mathrm{M} \mathrm{NaCl}\right.$ or $\left.1 \mathrm{M} \mathrm{CaCl}_{2}\right)$, were prepared. Then $250 \mu \mathrm{L}$ of sunflower oil was added to $2.25 \mathrm{~mL}$ of the ND dispersions. Finally, probe sonication with a power of $6 \mathrm{~W}$ and a sonication time of $2 \mathrm{~min}$. was used to prepare the Pickering emulsions.

\subsection{Emulsion characterization}

\subsubsection{Size and zeta potential of ND}

Dynamic light scattering (DLS) and zeta potential measurements of the ND dispersions and Pickering emulsions prepared by sonication were performed using a Malvern Zetasizer at an optimal temperature $\left(25^{\circ} \mathrm{C}\right)$. The instrument was fitted with a $4 \mathrm{~mW} 632.8 \mathrm{~nm}$ He-Ne red laser and a detector (avalanche photodiode) measuring the intensity of the scattered light positioned at $173^{\circ}$. All the dispersions were diluted (about 10 to 100 times) until a single peak and well fitted results were obtained. Reported values of size are volume-averages from three individual measurements and each individual measurement is the sum of 12 runs.

\subsubsection{Morphological observations}

The microstructures of the Pickering emulsions were observed with an optical microscope (Olympus BX53M), equipped with $10 \times, 20 \times$, and $50 \times$ objective lenses. The samples were prepared by placing several drops of emulsion on clean glass slides. Reflected and transmitted light sources were used. Digital images were analysed using the Analyse Particle function with Image $\mathbf{J}$ software to find the distribution of droplet sizes and the coefficient of variation, $\mathrm{CV},[45]$ in a routine in which the scale and contrast were set, the background subtracted, the image was binarized, and the cross-sectional areas were calculated. At least two images were analysed to determine the size distribution for each emulsion. For each image, at least 100 droplets were counted. Diameters of the oil droplets were determined 
from the areas of each droplet image, and mean values are reported hereafter to represent the droplet size.

An atomic force microscope (AFM, Dimension Edge ${ }^{\mathrm{TM}}$, Bruker) was used to characterize the morphology of ND coatings. To prepare these coatings, a ND dispersion (5 $\mathrm{mg} / \mathrm{mL}$ ) was spin coated (PWM32 photoresist spinner, Headway Research) onto glass coverslips at $3000 \mathrm{rpm}$. The glass coverslips were cleaned by immersion in acetone and ultrasonicated for 15 min., followed by a UV-ozone treatment (Bioforce Nanosciences Inc., model UV.TC.EU.003) for $20 \mathrm{~min}$ before use.

\subsubsection{Three-phase contact angle analysis}

To characterize the hydrophilicity balance of the ND as a function of $\mathrm{pH}$, the threephase contact angle at the contact line of oil, water, and a ND coating was measured using a contact angle analyser (Krüss, model DSA25B) at a room temperature of $21{ }^{\circ} \mathrm{C}$. A schematic diagram of the measuring technique is shown in Fig. S3. Firstly, a ND coating was deposited by spin coating a $5 \mathrm{mg} / \mathrm{mL}$ ND dispersion onto clean silicon wafer (100 orientation) at 3000 rpm. Next, the ND coating was placed at the bottom of a transparent chamber and covered by a thin layer of the sunflower oil. Then a $4 \mu \mathrm{L}$ water droplet (at different $\mathrm{pH}$ values, adjusted with $\mathrm{HCl}$ or $\mathrm{NaOH}$ solutions) was dropped through the oil and deposited onto the ND coating, because of its greater density. In this step, the top of the water droplet was partially exposed to the air to help it attach onto the ND coating, aided by capillarity and gravity. Finally, more oil was added to immerse the entire water droplet. The three-phase contact angle was recorded 10 min. later by capturing an image through the transparent walls of the chamber. Three different drops were analysed for each type of sample, and the mean values are reported. This methodology allows the study of the $\mathrm{pH}$ effect on the hydrophilicity of the ND phase. The measurements were influenced by the pre-wetting of the ND by the oil phase. If the ND were instead pre-wetted by the water phase, the less dense oil could not be dropped through the water onto the ND, because of buoyancy effects.

\subsubsection{Interfacial tensiometry}

A drop shape analyser (Krüss, FTA DSA1000B) was used for pendant drop tensiometry to measure the interfacial tension at the interface between the oil and ND dispersions of varying concentrations and $\mathrm{pH}$ value or between the oil and $\mathrm{DI}$ water with varying $\mathrm{pH}$. In this experiment, $0.5 \mathrm{mg} / \mathrm{mL}$ ND dispersions with different $\mathrm{pH}$ and different $\mathrm{NaCl}$ concentrations were prepared, and an ND dispersion drop with a volume of approximately $7 \mu \mathrm{L}$ was injected 
and hung from a $0.5 \mathrm{~mm}$ diameter needle in the less dense oil phase. Then through analysis of the drop shape using the video camera system on the apparatus (FTA32 software), the interfacial tension value was compared for various dispersion-oil interfaces. The experiments were conducted in a temperature-controlled room with a temperature of $22+/-1{ }^{\circ} \mathrm{C}$.

The forces that determine the shape of the pendant drop are mainly the balance of surface tension, buoyancy force and gravitation. The surface tension seeks to minimize the surface area and make the drop take a spherical shape. The difference of gravitation and buoyancy force, on the other hand, stretches the drop from this spherical shape and a typical pear-like shape results. The interfacial tension for a drop with a diameter of $D_{e q}$ at its equator was calculated as:[46]

$\gamma=\frac{\Delta \rho \cdot g D_{e q}{ }^{2}}{H}$

where $\Delta \rho$ is the density difference between water and oil, $g$ is the acceleration due to gravity (taken as $9.8 \mathrm{~m} / \mathrm{s}^{2}$ ), and $H$ is a shape factor that is decided by the shape of the drop. Here, the water density was taken to be $\rho_{\mathrm{w}}=0.998 \mathrm{~g} / \mathrm{cm}^{3}$ (obtained from the FTA32 software), and the density of sunflower oil [47] was taken as $\rho_{\mathrm{o}}=0.918 \mathrm{~g} / \mathrm{cm}^{3}$. Six replicate measurements were performed on the sunflower oil/DI water interface. The standard deviation was $0.4 \mathrm{mN} / \mathrm{m}$.

\subsubsection{Mechanical stability}

A shaking machine (OS 2 Basic Shaker, Yellowline by IKA) was used to compare the stability of ND-stabilized Pickering emulsions prepared in $\mathrm{pH} 4$ and $\mathrm{pH} 1.5$ buffers by membrane emulsification. $2 \mathrm{ml}$ of emulsions were put into $3 \mathrm{ml}$ vials and then set in a shaking machine at $300 \mathrm{rpm}$. After a specific shaking period, droplets of emulsion were imaged under the microscope and the size distributions were determined.

\subsubsection{Long-term emulsion stability}

For the ND-stabilized Pickering emulsions prepared by membrane emulsification, the prepared emulsions were stored for a certain period of time in the dark, then were dropped on glass-slides and observed under the optical microscope. By comparing the size differences of the emulsion drops stored for different periods of time, the storage stability was determined.

For the ND-stabilized Pickering emulsions prepared by probe sonication, the creaming index was used to compare the stability of emulsions fabricated under different $\mathrm{pH}$. 
The Pickering emulsion ( $3 \mathrm{~mL}$ ) prepared by probe sonication was monitored for a period of 300 hours. At regular time intervals, the height of the serum layer, $H_{\mathrm{S}}$, was observed by eye and measured with a ruler. The creaming index (CI) was calculated according to Eq. (2)[48]:

$\mathrm{CI}=100 \% \times \frac{H_{S}}{H_{e}}$

where $H_{\mathrm{e}}$ is the total emulsion layer height, as is illustrated in Fig. S4.

\subsubsection{Buffer addition to ND-stabilized Pickering emulsions}

$1 \mathrm{~mL}$ of buffers with different $\mathrm{pH}$ values were dropped into a chamber, then emulsions $(25 \mu \mathrm{L})$ prepared via membrane emulsification were dropped on the buffer under the optical microscope. (The emulsion volume fraction in the mixture was low, so that the final $\mathrm{pH}$ corresponds to the added buffers) A video camera connected to the optical microscope was used to record the emulsion behaviour immediately after the buffer addition.

\subsubsection{Drying stability of emulsion with an active ingredient}

$0.3 \mathrm{~g} \beta$-carotene powder was mixed with $3 \mathrm{~mL}$ sunflower oil before membrane emulsification in a ND dispersion $(0.5 \mathrm{mg} / \mathrm{mL})$ following the method in Section 2.2. The $\beta$ carotene imparted a yellow tint to the oil phase, which was visible under the optical microscope. The resulting emulsion containing $\beta$-carotene in the oil phase was mixed with the same volume of a standard ND Pickering emulsion.

A sample cell, as is shown in Fig. S5, was constructed for an emulsion drying experiment. The emulsion mixtures were dropped at the edge of the sample cell. After the sample cell was filled with an emulsion by capillary action, it was then put under the microscope to observe the drying and coalescence process.

\section{Results and discussions}

A representative optical microscope image of a ND-stabilized Pickering emulsion prepared by membrane emulsification is shown in Fig. 1. The ND concentration in $\mathrm{pH} 4$ buffer solution was $0.5 \mathrm{mg} / \mathrm{mL}$ (or $0.05 \mathrm{wt} . \%$ ). For comparison, an emulsion prepared using Tween $20(20 \mathrm{mg} / \mathrm{mL}$ in water) is also shown. Both emulsions were produced with a $40 \mu \mathrm{L} / \mathrm{min}$ injection rate and a $900 \mathrm{rpm}$ paddle stirring speed. Note that our concentration of ND particles here is nearly two orders of magnitude lower than the concentration of silica nanoparticles (4 wt.\%) that was used by Manga et al.[49] in their rotational membrane emulsification method 
to obtain a narrow size distribution of oil droplets in water. This is an indication of the effectiveness of the ND as a Pickering stabiliser. Having established that Pickering emulsions could be manufactured using membrane emulsification with carboxylated ND stabilizers, we proceeded to conduct a series of experiments to understand how the ND function in this application.
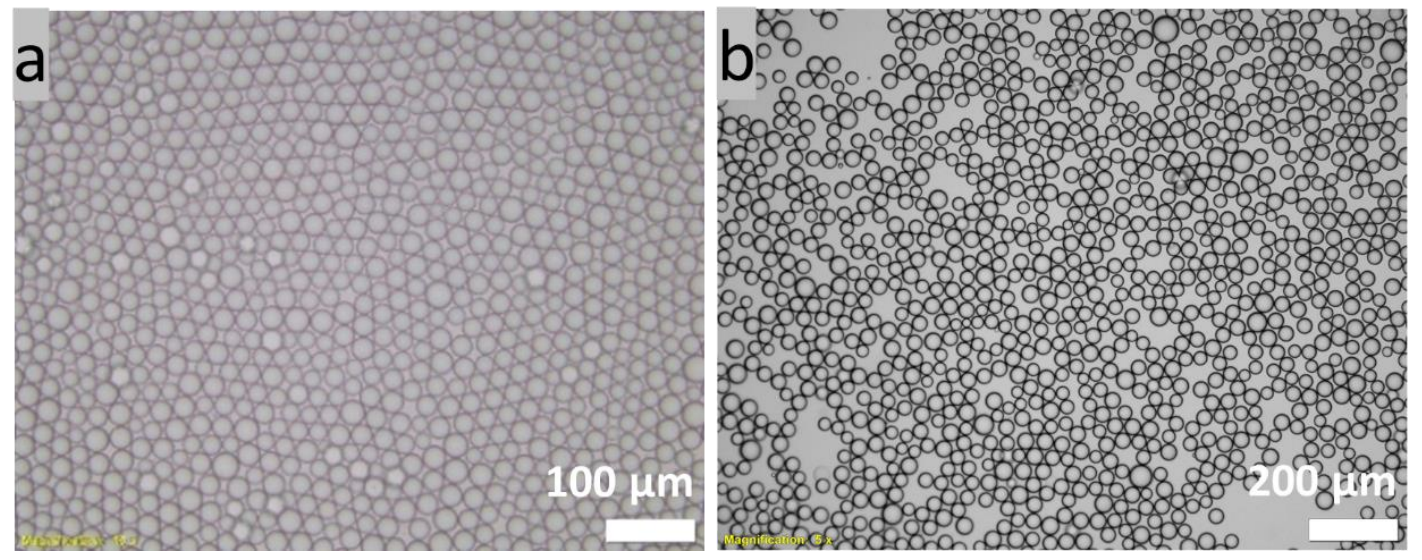

Fig. 1. Microscope images of emulsions made via membrane emulsification, stabilized using (a) $20 \mathrm{mg} / \mathrm{mL}$ of Tween 20 aqueous solution (mean size of $24 \mu \mathrm{m}$ and a CV of 8.6\%); (b) 0.5 $\mathrm{mg} / \mathrm{mL}$ ND dispersion in $\mathrm{pH} 4$ buffer (mean size of $32 \mu \mathrm{m}$ and a $\mathrm{CV}$ of $11 \%$ ).

\subsection{ND dispersions}

\subsubsection{Effect of $\mathrm{pH}$ and the presence of salt on ND dispersions}

Because of the relevance of charge stabilization, a study of the colloidal properties of the ND dispersions as a function of $\mathrm{pH}$ was conducted to understand the stability induced by their addition to Pickering emulsions. Thus, $0.5 \mathrm{mg} / \mathrm{mL}$ ND dispersions in DI water were prepared, adjusting the $\mathrm{pH}$ by adding either $\mathrm{HCl}$ or $\mathrm{NaOH}$ solutions. Dispersions containing 1 $\mathrm{M} \mathrm{NaCl}$ and $1 \mathrm{M} \mathrm{CaCl}_{2}$ were studied for comparison.

As is shown in Fig. 2, zeta potential values at $\mathrm{pH} \geq 4$ are more negative than $-25 \mathrm{mV}$ and the size of aggregates determined by DLS was $33 \mathrm{~nm}$, making the dispersion clear and with no sedimentation over a prolonged time. Under higher $\mathrm{pH}$ conditions, the carboxylic groups are largely deprotonated and negatively charged as $\mathbf{- C O O}^{-}$. Then, electrostatic repulsive forces between adjacent ND particles become stronger, thereby reducing the possibility of flocculation. [40][50] Interestingly, at $\mathrm{pH} 12 \mathrm{NaOH}$, the presence of $\mathrm{Na}^{+}$ions reduces the electrostatic repulsion between particles, which considerably reduces the absolute value of the zeta potential.[51] In contrast, at $\mathrm{pH} 2$, the zeta potential was close to 0 , and large aggregates of about $2 \mu \mathrm{m}$ in size were formed. This result can be explained by the protonation of the 
carboxylic acid groups on the surface of ND and the removal of the charge stabilization at the higher $\mathrm{pH}$.

Zeta potential and particle size measurements in $1 \mathrm{M} \mathrm{NaCl}$ and $1 \mathrm{M} \mathrm{CaCl}_{2}$ solutions (without $\mathrm{pH}$ adjustment) are also compared in Fig. 2. Zeta potential values for $1 \mathrm{~mol} / \mathrm{L} \mathrm{NaCl}$ and $1 \mathrm{~mol} / \mathrm{L} \mathrm{CaCl}_{2}$ were -8 and $6 \mathrm{mV}$, respectively. These results are inconclusive, however, owing to sedimentation occurring within 5 min, making the measurements unreliable. What can be stated is that the zeta potential was near zero, which can be explained by the electrostatic shielding of the COO- groups by the ions[52][53] being more effective for the divalent cation $\mathrm{Ca}^{2+}$ than for the monovalent cation $\mathrm{Na}^{+}$. Moreover, the presence of divalent $\mathrm{Ca}^{2+}$ ions may bridge adjacent ND particles, suppressing their electrostatic repulsion, and eventually leading to the observed flocculation.[54]
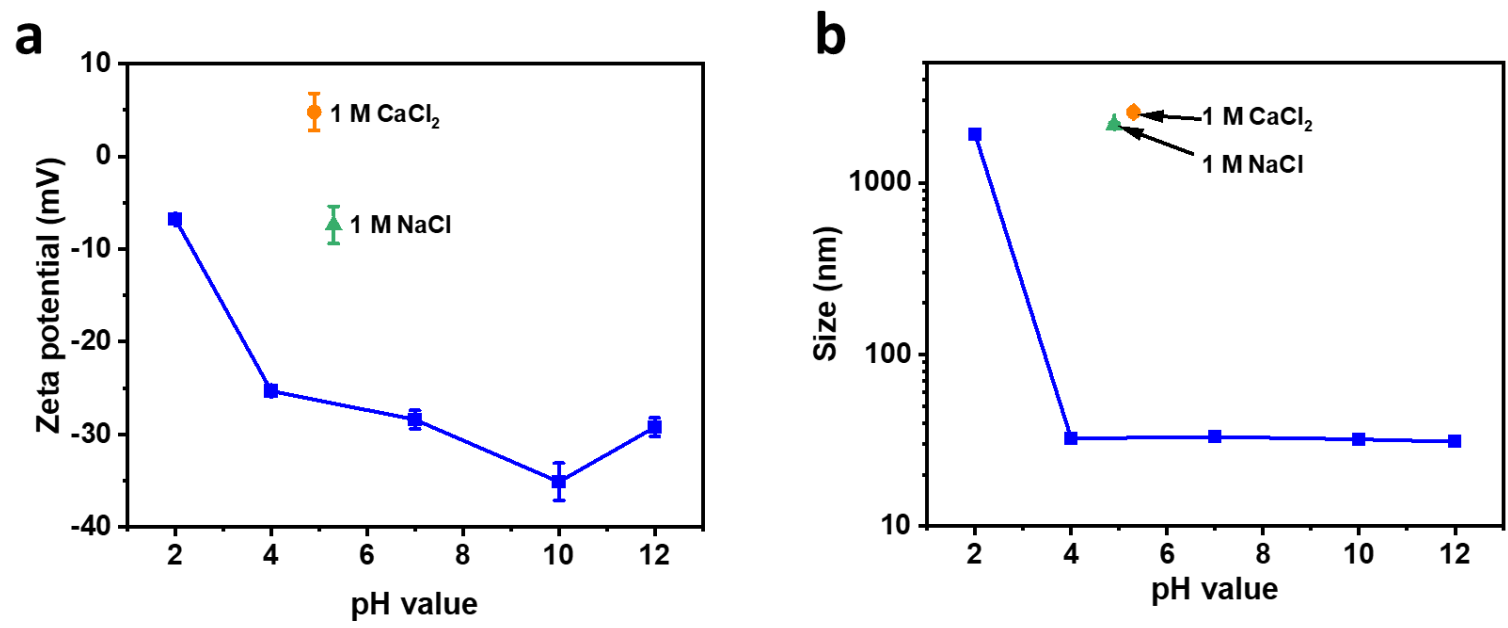

Fig. 2. Zeta potential and mean particle size as a function of the $\mathrm{pH}$ value of ND dispersions $(0.5 \mathrm{mg} / \mathrm{mL}$ ) adjusted with $\mathrm{HCl}$ and $\mathrm{NaOH}$ (blue squares), in comparison to $0.5 \mathrm{mg} / \mathrm{mL} \mathrm{ND}$ dispersions in $1 \mathrm{M} \mathrm{NaCl}$ (green triangles) and $1 \mathrm{M} \mathrm{CaCl}_{2}$ (orange circle) solutions.

Also, buffer solutions with a range of $\mathrm{pH}$ values $(1.5,4,7,9$, and 12) were used to dilute the ND dispersions to concentrations of $0.5 \mathrm{mg} / \mathrm{mL}$. It was found that for $\mathrm{ND}$ in $\mathrm{pH} 1.5$ and $\mathrm{pH}$ 4 dispersions, sediments appeared at the bottom of the vessel, suggesting clusters formed in this condition. When a $\mathrm{pH} 7$ or $\mathrm{pH} 9$ buffer solution was used, the ND remained well dispersed, making a brown coloured and translucent dispersion. However, when the ND dispersion was diluted in a pH 12 buffer, sediments formed again. Though a more alkaline environment would fully deprotonate carboxylic groups to charged $-\mathrm{COO}^{-}$which increases the repulsion force between ND particles, the $\mathrm{pH} 12$ buffer contains a high concentration of cations $\left(\mathrm{Ca}^{2+}\right)$, which 
effectively shield negative charges of carboxylic groups in ND, and may also bridge neighbouring ND, as mentioned above, leading to strong ND aggregation.

\subsubsection{Wettability of ND coatings characterized by the three-phase contact angle}

Particle wettability, characterized by the three-phase contact angle, $\theta$, is a key parameter that dictates the formation, type, and the stability of solid-stabilized emulsions.[55] The energy, $E$, required to remove a nanoparticle from an oil/water interface into the water phase is given as:

$$
E=\pi R^{2} \gamma_{w o}(1-\cos \theta)^{2}
$$

where $\gamma_{w o}$ is interfacial tension of the bare oil/water interface, and $R$ is the radius of the nanoparticle. (The sign before $\cos \theta$ is positive for the removal of the particle to the oil phase).

The three-phase contact angles (between oil, a carboxylic ND coating, and water) for water droplets with a range of $\mathrm{pH}$ values, adjusted with $\mathrm{HCl}$ or $\mathrm{NaOH}$ solutions, were compared. The morphology of the ND coating is shown in Fig. S6, where it is seen that a dense layer of ND is formed on glass coverslips.

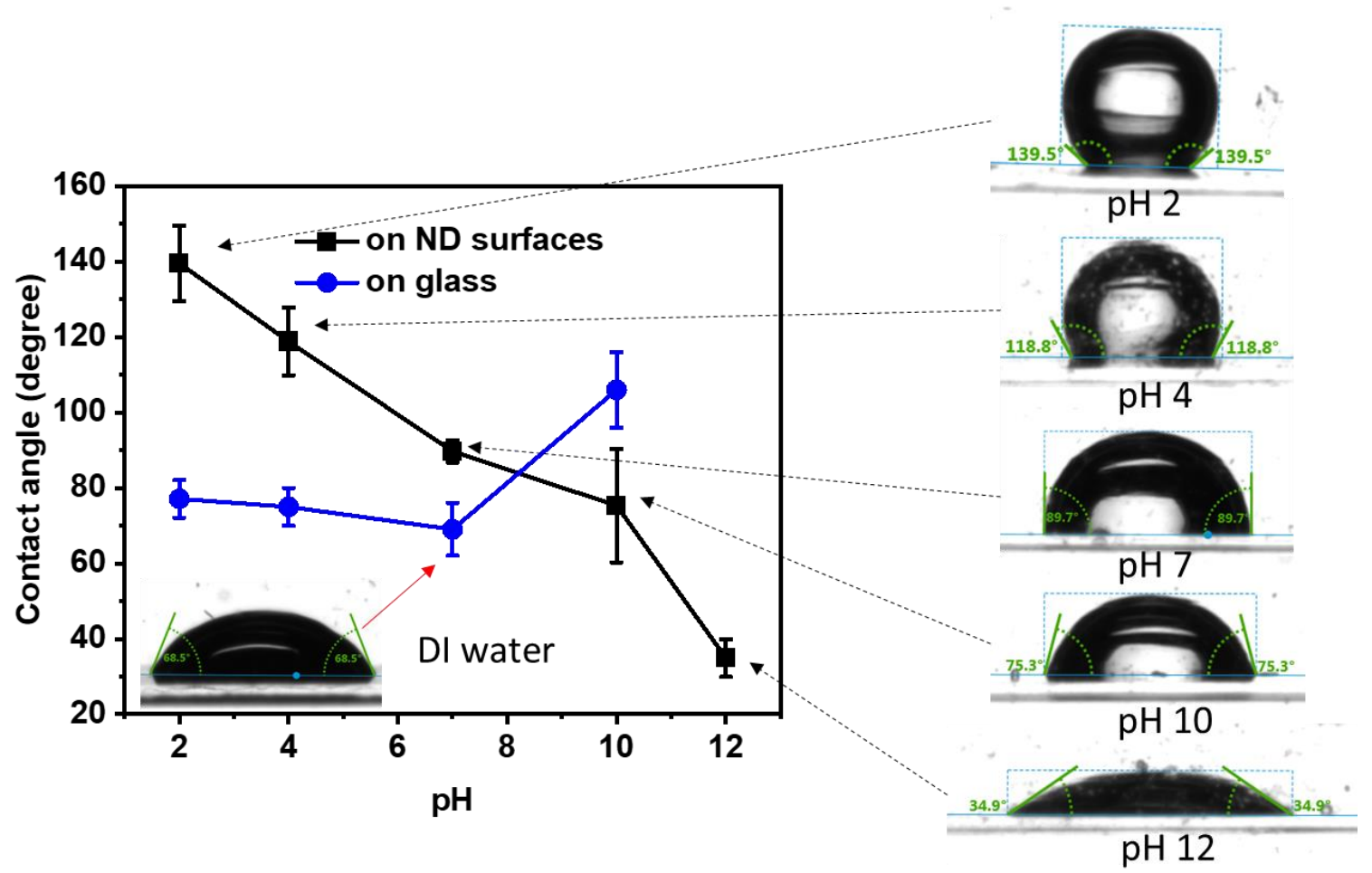

Fig. 3. Three-phase (oil/ND coating/water) contact angle for water droplets of different $\mathrm{pH}$ values (adjusted by $\mathrm{HCl}$ and $\mathrm{NaOH}$ ) attached to ND coatings (or glass) in a sunflower oil phase. Photographs of representative water drops on ND surfaces in the oil phase are shown. 
Values of $\theta$ are shown in Fig. 3 over a range of $\mathrm{pH}$. Measurements on uncoated glass are shown for comparison to the ND surface. As the $\mathrm{pH}$ of the aqueous droplet increases from $\mathrm{pH} 2$ to $\mathrm{pH} 12$, the contact angle decreases to values below those measured for uncoated glass. This result is consistent with our finding that higher $\mathrm{pH}$ values lead to deprotonation of carboxylic groups on the ND surface, which makes it more hydrophilic. The results reveal that because of its effect on $\theta$, the $\mathrm{pH}$ will influence the suitability of the ND to function as Pickering stabilizers. However, we note that the ND was pre-wetted with the oil in this measurement. Furthermore, the coating's roughness and surface imperfections will affect the value of $\theta$, and hence there is uncertainty in its measurement.

We attempted an alternative method in which sessile drops of water were placed on the ND films in air. The water was fully wetting of the ND in air, across the entire range of $\mathrm{pH}$. When oil was added on top, however, the water did not dewet the ND, perhaps because the film is particulate.

For aqueous drops at different $\mathrm{pH}$ values on clean glass, the three-phase contact angle did not significantly change until the $\mathrm{pH}$ of the aqueous phase was increased to 10 , where the contact angle rose to over $100^{\circ}$ (Fig. 3). This result can be explained by consideration of the oil chemistry. When the vegetable oil, whose main component is a triglyceride, is in contact with an alkaline environment at the interface with the water, a hydrolysis reaction, which is known as saponification,[56] will occur. The reaction process is given as:

\section{$\mathrm{CH}_{2} \mathrm{COOCR}-\mathrm{CH}_{2} \mathrm{COOCR}-\mathrm{CH}_{2} \mathrm{COOCR}+3 \mathrm{NaOH} \longrightarrow 3 \mathrm{RCOONa}+\mathrm{C}_{3} \mathrm{H}_{5}(\mathrm{OH})_{3}$}

As a result of the saponification, anionic surfactants (RCOO-) will be produced at the interface between the aqueous phase and oil, where the hydrophobic $\mathrm{R}$ tails will be exposed to the surrounding oil and the hydrophilic heads COO- in contact to the aqueous phase, which reduces the interfacial energy between water and oil, thus increasing the contact angle to over $100^{\circ}$. Moreover, when the $\mathrm{pH}$ was increased to 12 , the aqueous drops detached from the glass, making a measurement impossible. Saponification of the oil under alkaline conditions is further confirmed by emulsification experiments and infrared spectroscopy presented in Fig. S7 and S8.

\subsubsection{Interfacial tensiometry with ND at oil/water interfaces}

To gain insight into the emulsification process and to investigate the transfer of ND from the water phase to the interface with oil, we used pendant drop tensiometry. The 
interfacial tension, $\gamma_{o w}$, between sunflower oil and water has been reported elsewhere[57] to be $23.91 \mathrm{mN} / \mathrm{m}$. In our measurements $\gamma_{o w}$ was initially $23.9 \mathrm{mN} / \mathrm{m}$, and then the value decreased gradually toward equilibrium over time, as is shown in Fig. S9. This decrease is likely arising from trace chemical impurities within the sunflower oil or in the DI water slowly adsorbing at the interface. In replicate measurements of interfacial tension on the oil/water interface, the values were typically reproduced within $0.5 \mathrm{mN} / \mathrm{m}$. We estimate that the uncertainty of the measurement is less than $1 \mathrm{mN} / \mathrm{m}$.

Because the Pickering emulsions used DI-water and as-received sunflower oil, the pendant drop tensiometry was performed on these same two liquids without further purification, as our intention is to gain insight into the Pickering emulsification. Note that although the impurities in the system reduced the interfacial tension over time, stable emulsions of DI water and sunflower oil alone could not be prepared via membrane emulsification. There was an immediate phase separation. The presence of ND at the interface was essential.

To investigate the interfacial activity of the ND, we measured the effect of its concentration, $c$, on the interfacial tension, as is shown in Fig. 4a. With an increase of $c$ from $0.1 \mathrm{mg} / \mathrm{mL}$ to $10 \mathrm{mg} / \mathrm{mL}$, the value of interfacial tension decreased noticeably and consistently. Using the data collected at a time of $4 \mathrm{~h}$ for each sample, $\gamma$ is inversely and linearly dependent on $\log c$ (see the inset), which is congruent with the literature where interfacial activity increased with the concentration of nanoparticles at an oil/water interface.[58] In this previous report, the interfacial tension likewise decreased linearly with the in-plane pressure of nanoparticles at that interface, which depends on the product of the nanoparticle packing density and the compressibility. These results provide evidence that the ND is being adsorbed at the oil/water interface with an increasing packing density, $\eta$.

In Figure $4 \mathrm{a}$, there is a decrease in the surface tension of approximately $3 \mathrm{mN} / \mathrm{m}$, which we attribute to ND adsorption at the oil/water interface. If, at the highest ND concentration, the ND clusters (diameter of $33 \mathrm{~nm}$ ) create a close-packed layer at the oil/water interface (with a hexagonal packing fraction of $\eta=0.91$ ), then the change in the energy is estimated to be $2 \times$ $10^{-18} \mathrm{~J}$, following the derivation of Du et al.. If the three-phase contact angle is taken to be $\theta=$ $50^{\circ}$, we estimate using Equation 3 that the binding energy $E$ for the ND cluster at the oil/water interface is likewise $2 \times 10^{-18} \mathrm{~J}$. Thus, the results in Figure $4 \mathrm{a}$ are consistent with the expectations of ND clusters being present at the oil/water interface. 
Having established interfacial activity, we then investigated the effect of the concentration of $\mathrm{NaCl}$ in the aqueous phase (ND dispersion) with a fixed concentration of $\mathrm{ND}$ $(0.5 \mathrm{mg} / \mathrm{mL})$. Fig. $4 \mathrm{~b}$ shows that there is an inverse relation between $\gamma$ and the $\mathrm{NaCl}$ concentration. The lowest value of $\gamma$ is shown with an $\mathrm{NaCl}$ concentration of $0.3 \mathrm{M}$. However, raising the $\mathrm{NaCl}$ concentration higher than $0.3 \mathrm{M}$ did not reduce the interfacial tension further. This is because when the salt concentration is raised, large ND aggregates form as a result of the electrostatic shielding effect (as was confirmed with DLS). Then, the aggregates are prone to sediment rather than staying in suspension where they can be adsorbed at the interface of the oil and water.
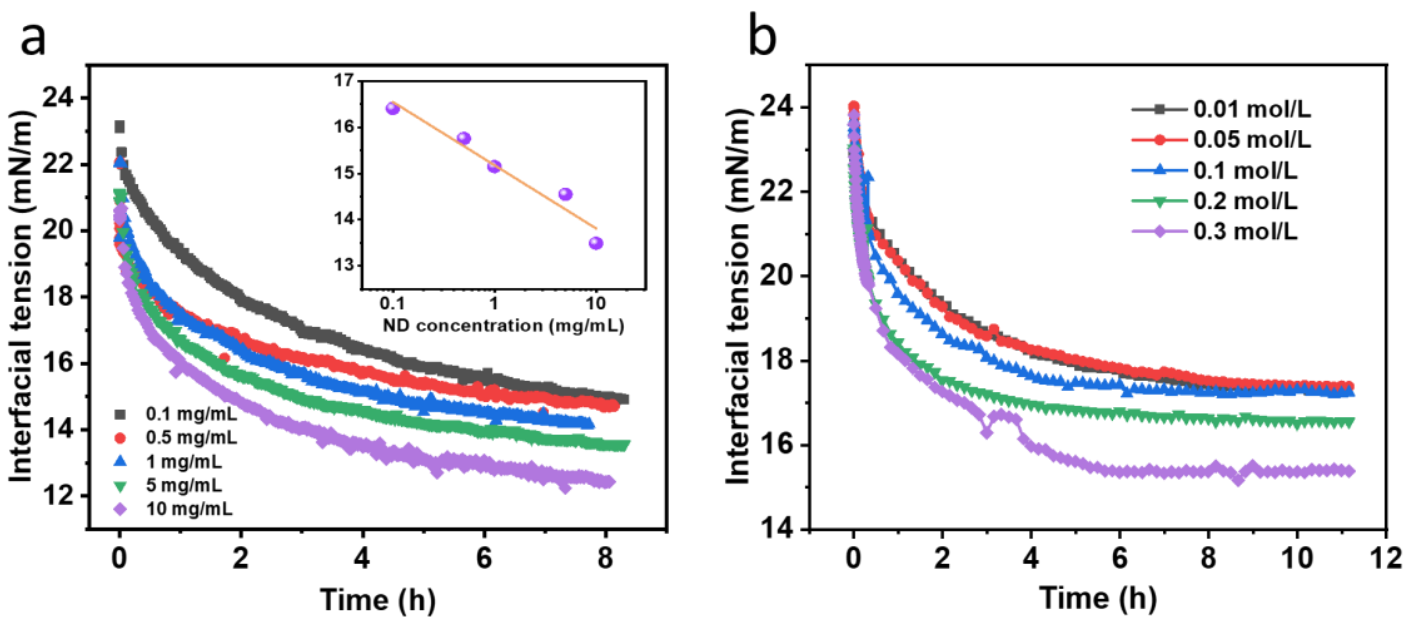

Fig. 4. (a) Interfacial tension of oil/water with increasing ND concentrations (from 0.1 to 10 $\mathrm{mg} / \mathrm{mL}$, as shown in the legend). The $\mathrm{pH}$ of the aqueous phase was not adjusted and is 7.4 in all experiments. The inset shows interfacial tension as a function of ND concentration according to the data recorded $4 \mathrm{~h}$ after the start. (b) Interfacial tension of oil/water with increasing concentrations of $\mathrm{NaCl}$ (from 0.01 to $0.3 \mathrm{M}$, as shown in the legend) in $\mathrm{ND}$ dispersions with a concentration of $0.5 \mathrm{mg} / \mathrm{mL}$.

We recall that with an increasing $\mathrm{pH}$ of the ND dispersions there was a decrease in the three-phase contact angle towards $90^{\circ}$, thereby making them optimal for Pickering stabilizers. To separate out the effects of $\mathrm{pH}$ and the presence of ND nanoparticles on the interfacial tension, we attempted measurements to compare $\gamma$ of oil interfaces with DI-water to that of ND dispersions $(0.5 \mathrm{~g} / \mathrm{mL})$ over a range of $\mathrm{pH}$ values from 2 to 10 . At the lowest $\mathrm{pH}$ values ( 2 and 4), sedimentation of the ND clusters and depletion of the concentrations made the measurements unreliable. No effect of the ND on interfacial tension was possible to discern. 
The effect of the ND in $\mathrm{NaOH}$ solution ( $\mathrm{pH}$ 10) was apparent when comparing to the equivalent water/oil interface. Whereas the interface with the ND dispersion at this $\mathrm{pH}$ was stable and allowed measurement indicating interfacial adsorption, there was a strong instability at the oil interface with the $\mathrm{pH} 10 \mathrm{NaOH}$ solution (Fig 5). The drop shape changed gradually from spherical to an irregular shape, as is shown in the inset and in Video S1, which prevented a valid measurement. This latter result can be explained by surfactants being produced via saponification (as explained in 3.1.2). For $\mathrm{pH} 12 \mathrm{NaOH}$ solutions in oil (not shown here), the drop detached from the needle quickly even before the droplet volume reached $3 \mu \mathrm{L}$, indicating a very low interfacial tension at this $\mathrm{pH}$. In contrast, when ND in a $\mathrm{pH} 12 \mathrm{NaOH}$ solution was used, the drop was more stable and did not detach from the needle, most likely because ND are covering and partially protecting the oil from saponification. This result shows an advantage of using ND as a stabilizer in emulsions.

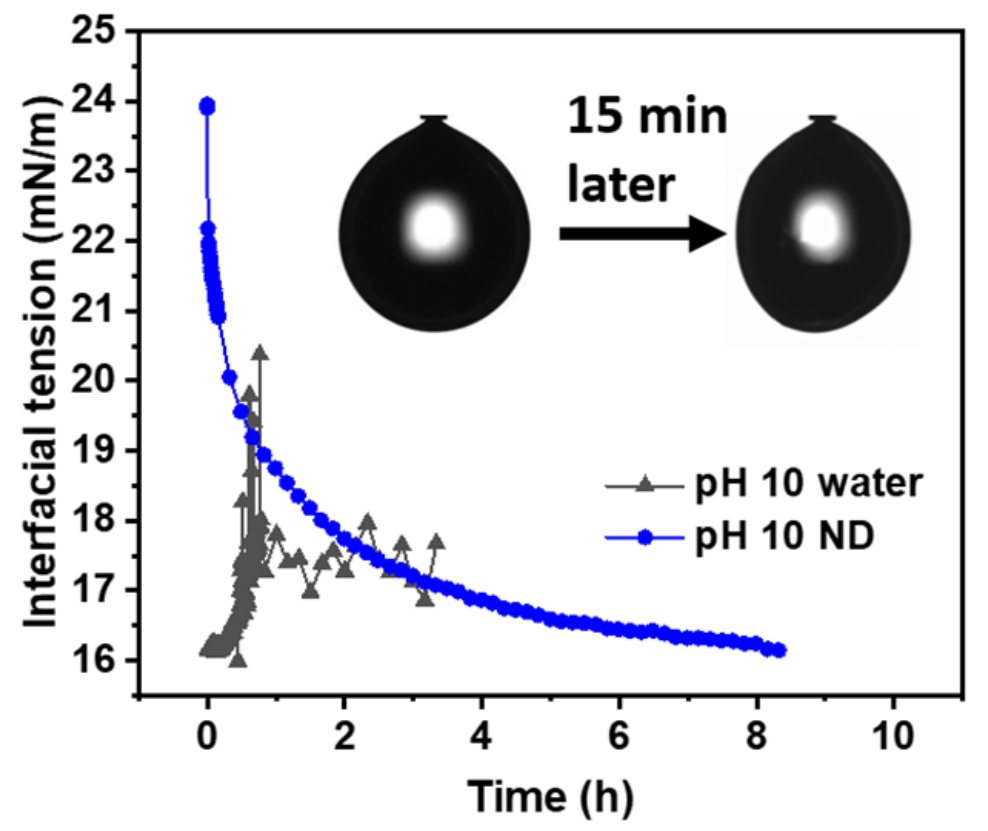

Fig. 5. The interfacial tension of water and oil (black triangles) compared to that of an ND dispersion in water $(0.5 \mathrm{mg} / \mathrm{mL})$ and oil (blue circles) at $\mathrm{pH} 10$ (adjusted with $\mathrm{NaOH}$ ). The inset shows images to illustrate the shape changes of a $\mathrm{pH} 10 \mathrm{NaOH}$ water drop (without ND) before and after being immersed in oil for $15 \mathrm{~min}$. See Video S1 (Supplementary Materials) to observe the changes over time.

\subsection{Carboxylated ND-stabilized Pickering emulsions}

The carboxylated ND in DI-water carry a negative surface charge, and electrostatic repulsions between charged particles can act against the adsorption at the oil/water 
interface.[59] However, a progressive screening of the charge occurs with increasing ionic strength. Thus, as we describe hereafter, stable ND-stabilized Pickering emulsions could be prepared in buffer solutions. The electrolytes contained at low concentration in buffers screen the surface charges of ND, and promote the ND being adsorbed to the oil/water interface, thus assisting in the emulsion stabilization.

\subsubsection{ND- stabilized Pickering emulsions by membrane emulsification}

Having established an understanding of the interfacial activity of ND and the effects of $\mathrm{pH}$ and salt, we prepared ND-stabilized Pickering emulsions with narrow size distributions using the method of membrane emulsification. Results from using $20 \mathrm{mg} / \mathrm{mL}$ sunflower oil in $0.5 \mathrm{mg} / \mathrm{mL}$ ND dispersions in both $\mathrm{pH} 4$ and $\mathrm{pH} 1.5$ buffers are shown in Fig. 6. After the emulsions were stored in a container, a brown-tinted cream layer above the transparent serum layer was observed within $10 \mathrm{~min}$. The mean size of oil droplets prepared using ND in a $\mathrm{pH}$ 1.5 buffer is $38 \mu \mathrm{m}$ with a $\mathrm{CV}$ of $10.28 \%$. When the $\mathrm{pH}$ of the buffer solution has a higher value of 4 , the mean droplet size is $36 \mu \mathrm{m}$ with a $\mathrm{CV}$ of $7.78 \%$.

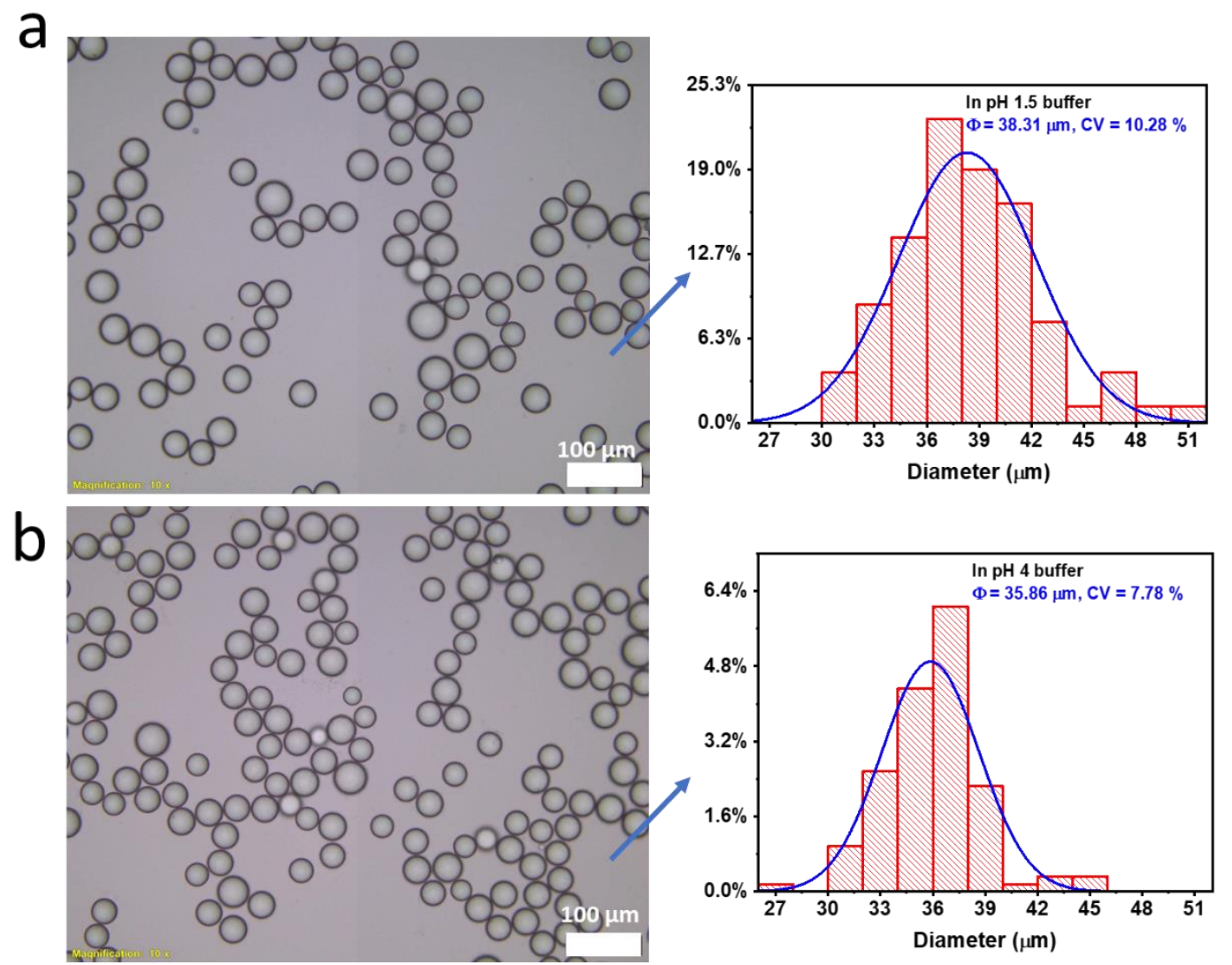

Fig. 6. ND-stabilized emulsions prepared by membrane emulsification using ND dispersion in buffers with (a) $\mathrm{pH} 1.5$ and (b) $\mathrm{pH} 4$ buffers. The injection rate here was $100 \mu \mathrm{L} / \mathrm{min}$, and the 
stirring speed was $900 \mathrm{rpm}$. The scale bar is $100 \mu \mathrm{m}$. The histograms of the same emulsions are shown on the right-hand side.

Notably, when the $\mathrm{pH}$ value of the buffer is raised to higher values ( $\mathrm{pH} 7$ and $\mathrm{pH}$ 9), the ND solutions do not make stable Pickering emulsions, apparently owing to the higher surface charge and hence greater hydrophilicity of the ND (Fig. 3), which results in poor interfacial adsorption of ND.[59]

Surprisingly, a ND dispersion in a pH 12 buffer solution does make Pickering emulsions, although they are less stable than emulsions made from $\mathrm{pH} 4$ solutions. This finding can be explained by the high concentration of ions $\left(\mathrm{Ca}^{2+}\right)$ in the $\mathrm{pH} 12$ buffer, which effectively shield negative charges of carboxylic groups in ND and produce ND aggregates. As mentioned above, ND sediments were also observed for dispersions in a $\mathrm{pH} 12$ buffer. Moreover, it has been reported that nanoparticle clusters aid the preparation of stable Pickering emulsions, by effectively creating a larger particle radius, $R$. [60,61]

\subsubsection{Long-term emulsion stability}

Long-term stability is always a very important issue for applications of emulsions. We therefore investigated the stability of the emulsions (made from $\mathrm{pH} 4$ and $\mathrm{pH} 1.5$ buffers) against coalescence under mechanical shaking and one-year of storage. As is shown in Fig. 7, the mean size and $\mathrm{CV}$ of both emulsions increased with prolonged shaking time. While for emulsions prepared in $\mathrm{pH} 1.5$ buffer, the mean drop size increased by $15 \%$ from $38.5 \mu \mathrm{m}$ to $44.4 \mu \mathrm{m}$ (Fig. 7a), for emulsions prepared in $\mathrm{pH} 4$ buffer, the mean size increased by $11 \%$ from $34.9 \mu \mathrm{m}$ to $38.8 \mu \mathrm{m}$ (Fig. $7 \mathrm{~b}$ ). We interpret this increase as resulting from the coalescence of only a fraction of oil droplets in the sample. Furthermore, the CV of the $\mathrm{pH} 1.5$ emulsions increased by $2.4 \%$ after 360 min. of mechanical shaking, while for $\mathrm{pH} 4$ emulsions $\mathrm{CV}$ increased by only $0.5 \%$. For both, the trend in $\mathrm{CV}$ over time was not obvious, and the absolute changes were relatively small.

To provide a comparison to these results, the stability of emulsions prepared using Tween 20 surfactant as the emulsifier (as in Fig. 1a) was investigated. After shaking, the particle size of these emulsions decreased from $22.3 \mu \mathrm{m}$ to $18.7 \mu \mathrm{m}$, and the $\mathrm{CV}$ changed from $12 \%$ to $37.5 \%$ over a time period of $6 \mathrm{~h}$. See Fig. S10. Thus, it can be concluded that the Pickering emulsions have greater stability when shaken than do the Tween 20-stabilized emulsions. Notably, the concentration of Tween 20 in the water phase $(20 \mathrm{mg} / \mathrm{mL})$ is 40 times higher than the ND concentration $(0.5 \mathrm{mg} / \mathrm{mL})$. 
a

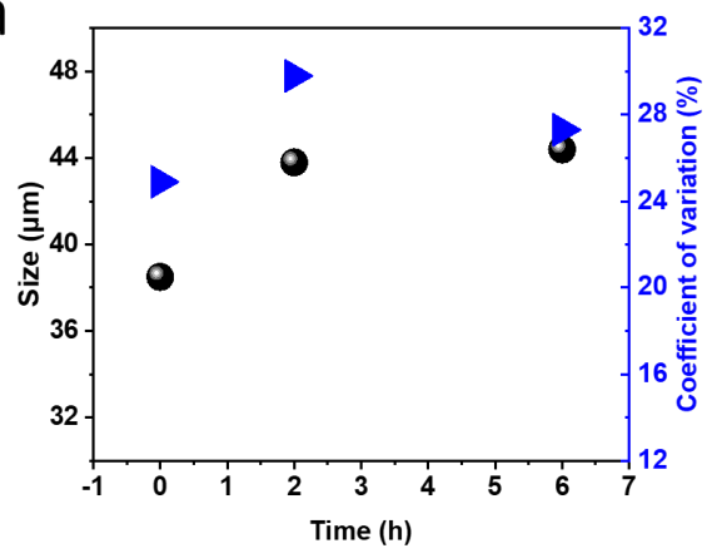

b

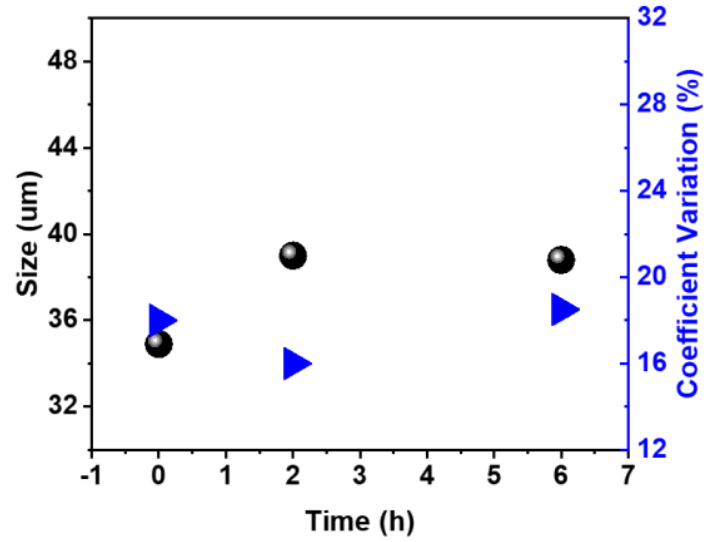

Fig. 7. Influence of the time of mechanical shaking on the mean oil droplet size (black circles) and $\mathrm{CV}$ (blue triangles) of Pickering emulsions prepared by membrane emulsification using ND dispersion in buffers with (a) $\mathrm{pH} 1.5$ and (b) $\mathrm{pH} 4$.

Emulsions prepared under both $\mathrm{pH}$ conditions were stored in the dark while stationary for approximately one year. After one year of static aging, there is no obvious change in the mean sizes of the two emulsions (see Fig. S11). There is, however, a small increase in the CV for both emulsions. From both the shaking and aging stability monitoring experiments, it is concluded that the ND-stabilized Pickering emulsions prepared in both $\mathrm{pH} 1.5$ and $\mathrm{pH} 4$ buffers by membrane emulsification have a high stability against coalescence.

\subsubsection{Effect of ND concentration on Pickering emulsions}

To gain a deeper insight into the emulsification process, a series of ND dispersions with different concentrations $(0.06 \mathrm{mg} / \mathrm{mL}, 0.08 \mathrm{mg} / \mathrm{mL}, 0.1 \mathrm{mg} / \mathrm{mL}, 0.5 \mathrm{mg} / \mathrm{mL}, 1 \mathrm{mg} / \mathrm{mL}, 1.5$ $\mathrm{mg} / \mathrm{mL}$, and $2 \mathrm{mg} / \mathrm{mL}$ ) in $\mathrm{pH} 4$ buffer were used to prepare Pickering emulsions by membrane emulsification. The resulting emulsions are shown in the optical microscope images in Fig. 8. At the two lowest ND concentrations, the oil drop size is polydisperse, but at the higher concentrations the oil drops are more monosize.

To allow valid comparison to the model presented by Tcholakova et al.,[62][63] the volume-surface diameter, $D_{32}$, was found via image analysis for each of these emulsions and presented in Fig. 8i. At the two lowest ND concentrations, $D_{32}$ decreases with increasing ND concentration. At concentrations of $0.1 \mathrm{mg} / \mathrm{mL}$ and higher, $D_{32}$ is independent of the ND concentration. These results show the same trend found in the data for emulsions stabilised by proteins and also by latex particles.[62][63] Using the language in this previous work, there is an emulsifier-poor region (I), in which smaller oil drops are created as more ND is added. There 
is also an emulsifier-rich region (II), in which any additional ND is in solution. The transition between Region I and II occurs when the ND's threshold value of adsorption, $\Gamma^{*}$. The data in Figure $8 \mathrm{i}$ show a transition between Regions I and II at $0.1 \mathrm{mg} / \mathrm{mL}$ ND. In support of this description, in the optical microscope images in Fig. 8, it is apparent that with an increase in ND concentration, more ND aggregates appear at the interface of oil and water. Fig. 8h shows a good example. Some free ND clusters are even visible in the water phase. Higher ND concentrations do not drive the formation of smaller oil droplets, but instead the ND appears as clusters in solution.

To gain an insight into the ND shell at the concentration corresponding to $\Gamma^{*}$, we employ a simple geometric model to estimate the minimum number of ND clusters to create a hexagonally-packed ND shell around the oil drops. (Drawing on the results in Figure 2, we note that the ND does not exist as primary $5 \mathrm{~nm}$ particles.) Our calculations are shown in the Supplementary Materials. We find that when a concentration of $0.1 \mathrm{mg} / \mathrm{mL}$ ND was used to stabilize $3 \mathrm{~mL}$ of oil in $27 \mathrm{~mL}$ of water, the number of ND nanoparticle clusters in the dispersion is $1.9 \times 10^{14}$, whereas $4.4 \times 10^{14}$ nanoparticle clusters are needed to cover the surfaces of all oil drop (number mean diameter of $36 \mu \mathrm{m}$ ). This rough estimate suggests with $0.1 \mathrm{mg} / \mathrm{mL}$ ND there are enough clusters to achieve an interfacial area coverage of $c a .40 \%$. When the ND concentration is higher than $0.25 \mathrm{mg} / \mathrm{mL}$, we estimate that $100 \%$ oil surface coverage by a single layer of close-packed ND clusters can be achieved, which suggests it would fall into Region II. In work elsewhere,[64] stable Pickering emulsions were obtained with a surface coverage as low as $5 \%$ of the area. Thus, our estimate of a surface coverage of approximately $40 \%$ is not unreasonable.

Farias et al. [33] found when using hydroxylated ND as stabilizers in sonicated emulsions that the oil drop size decreased with increasing concentrations of ND. Their results thus suggest that their system was still in Region I at ND concentrations as high as 2 wt.\% (approximately $20 \mathrm{mg} / \mathrm{mL}$ ). 


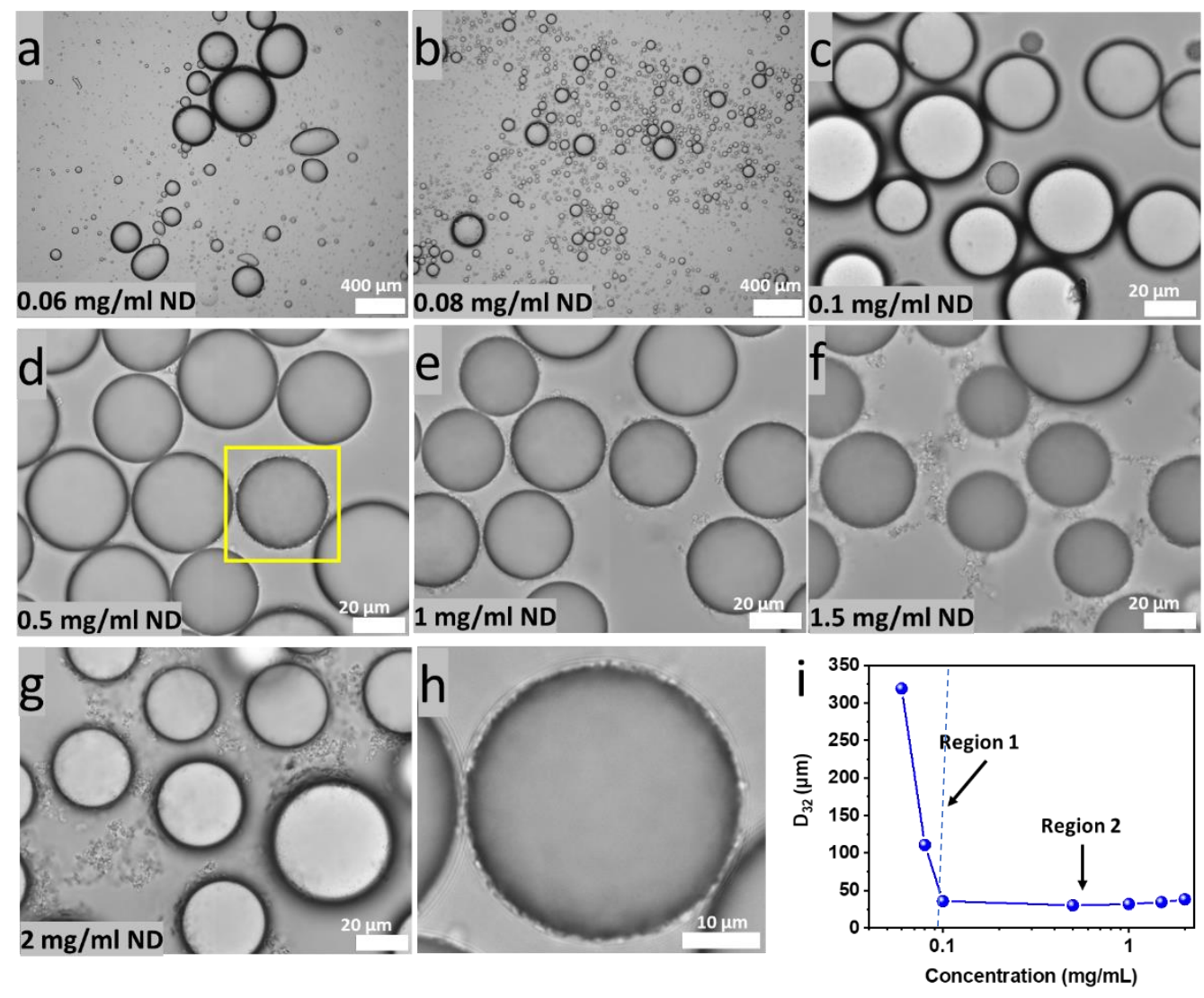

Fig. 8. Optical microscope images of ND-stabilized Pickering emulsions made by membrane emulsification with $\mathrm{pH} 4 \mathrm{ND}$ dispersions with concentrations of (a) $0.06 \mathrm{mg} / \mathrm{mL}$, (b) 0.08 $\mathrm{mg} / \mathrm{mL}$, (c) $0.1 \mathrm{mg} / \mathrm{mL}$, (d) $0.5 \mathrm{mg} / \mathrm{mL}$, (e) $1 \mathrm{mg} / \mathrm{mL}$, (f) $1.5 \mathrm{mg} / \mathrm{mL}$ and (g) $2 \mathrm{mg} / \mathrm{mL}$. (h) A magnified view of a single oil drop from the yellow square in d, showing a layer of ND clusters surrounding the oil drop. (i) Graph showing the $D_{32}$ size as a function of the ND concentration.

Further increasing ND concentrations to $1.5 \mathrm{mg} / \mathrm{mL}$ and $2 \mathrm{mg} / \mathrm{mL}$ imparts the emulsion with a high CV again (see in Fig. 8f). As the concentration is high enough to reach $100 \%$ coverage of the oil drop surface, the stability of a single oil drop does not change further.[65] It is known from other studies that if there are excess nanoparticles in the water phase, smaller oil droplets can form because there are sufficient numbers to encapsulate greater surface areas of oil.[66] As previously shown in the present work, ND form aggregates in $\mathrm{pH} 4$ buffer, which demonstrates that attractive forces between particles are dominant, therefore increasing the possibility of coalescence during membrane emulsification. Hence the CV increases, while the mean size remains the same. 


\subsubsection{Effect of $\mathrm{pH}$ changes on ND-stabilized Pickering emulsions}

Additional experiments investigated the stability of the Pickering emulsions against a “challenge" by a sudden $\mathrm{pH}$ change. $25 \mu \mathrm{L}$ of ND-stabilized Pickering emulsion was added to $1 \mathrm{~mL}$ of $\mathrm{pH} 12$ buffer. The response in the emulsion was observed on a glass slide under an optical microscope. A few oil droplets "exploded" abruptly upon the $\mathrm{pH}$ increase, with a sudden blurring of the oil/water interface (Fig. 9). The corresponding video can be found in the Supplementary Material (Video S2). This destabilization occurred for a wide range of ND concentrations $(0.5,0.75,1,1.5$ and $2 \mathrm{mg} / \mathrm{mL})$. When a $\mathrm{pH} 9$ buffer was used, the effect was slowed and also only a small fraction of the oil droplets was destabilized. Upon addition of lower $\mathrm{pH}$ buffers to the original Pickering emulsion, the emulsion remained stable with no oil drops being broken.
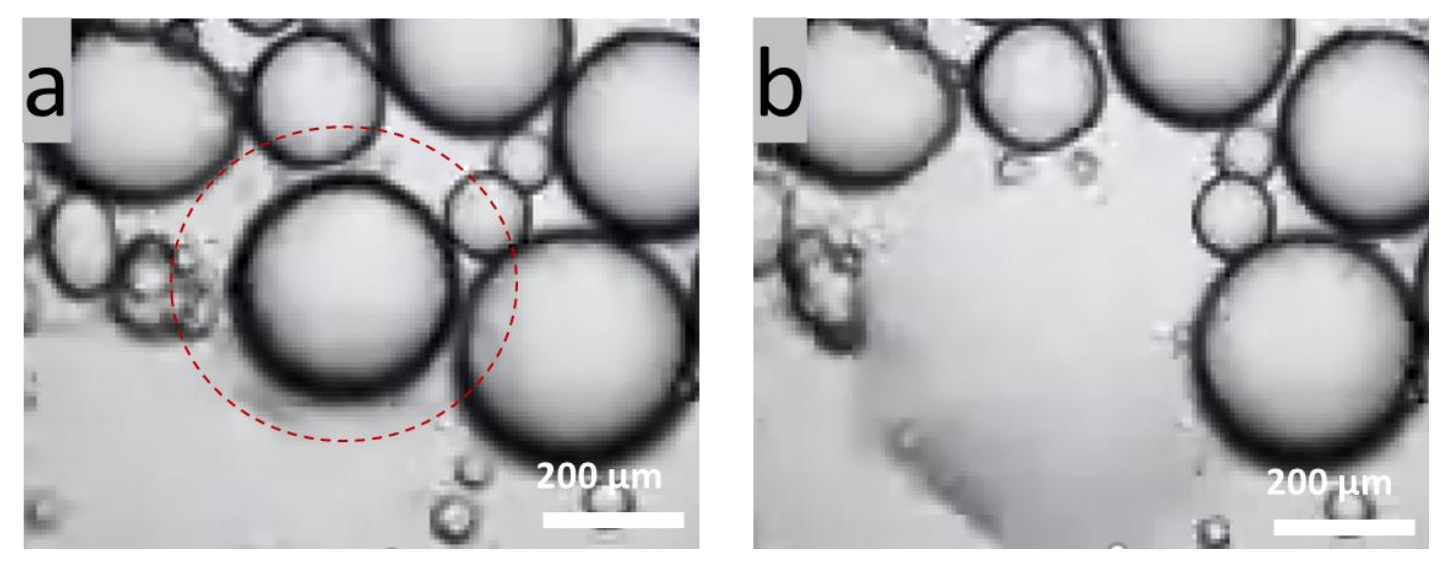

Fig. 9. Video stills showing the effect of $\mathrm{pH} 12$ buffer addition to a $0.1 \mathrm{mg} / \mathrm{mL}$ ND stabilized Pickering emulsion at pH 4 (a) before and (b) after an oil drop "explodes" instantaneously.

In the $\mathrm{pH} 12$ buffer, electrostatic screening by cations (including $\mathrm{Na}^{+}$or divalent cations $\mathrm{Ca}^{2+}$ ), present at high concentrations in the $\mathrm{pH} 12$ buffer media, could lead to ND aggregation at the oil/water interface. It has been reported that the lateral displacement of Pickering particles requires less energy compared to the displacement of particles into the continuous phase.[67] Thereafter, the exposure of the oil phase to the alkaline environment will result in fast saponification and the formation of anionic surfactants on the oil interface, thus reducing its interfacial tension. Consequently, the oil/water interface could be broadened. However, upon addition of the ND-stabilized Pickering emulsion to $\mathrm{pH} 12 \mathrm{NaOH}$ solution instead of $\mathrm{pH} 12$ buffer, no destabilization of droplets is observed, probably because ND aggregation at the oil/water interface does not take place and the surface coverage of ND on the drop surface is not altered. 


\subsubsection{Release of $\beta$-carotene upon emulsion drying}

We found that ND Pickering emulsions are able to carry $\beta$-carotene in the oil phase, suggesting a potential application as a carrier of hydrophobic active ingredients in an aqueous formulation. Under optical microscopy, oil droplets containing $\beta$-carotene can be seen to be tinted yellow (Fig. 10). Upon evaporation of water from the emulsion, the oil droplets pack closely together. There is evidence for coalescence between the ND-stabilized oil droplets observed under the microscope (Fig. 10b and c) as the boundary between them disappears and $\beta$-carotene is seen to diffuse into neighboring droplets, which is apparent from the color change.
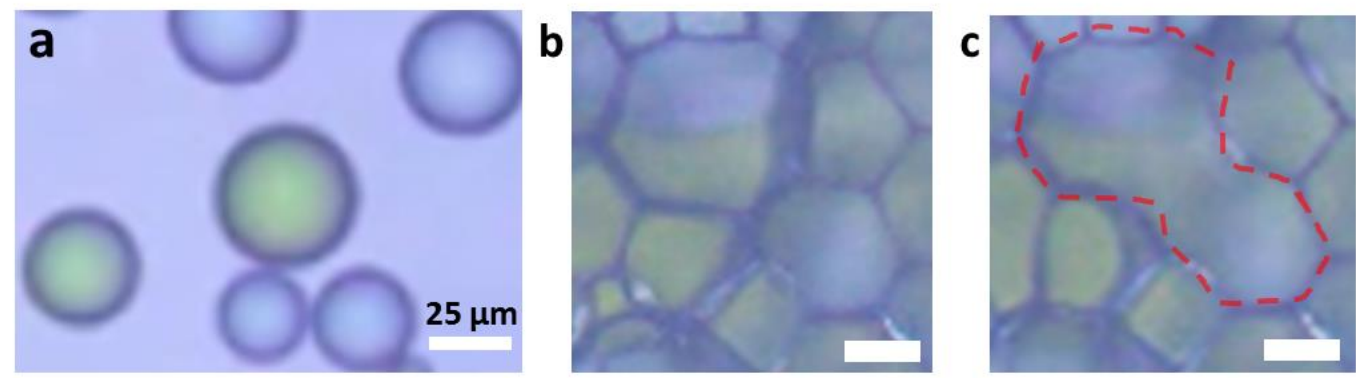

Fig. 10. (a) Optical microscope image of mixtures of oil droplets (with and without $\beta$-carotene) in ND Pickering emulsions. The droplets containing $\beta$-carotene have a yellow tint. Mixtures of oil droplets in an ND Pickering emulsion in the late stages of drying (b) when closely-packed and (c) after coalescence a few seconds later. The scale bar is $25 \mu \mathrm{m}$ in all images. The images in (b) and (c) are taken from Video S3.

\subsubsection{ND-stabilized Pickering emulsions by probe sonication}

The membrane emulsification method is good for making emulsions with a relatively large size $(10$ s of $\mu \mathrm{m})$ and with a narrow size distribution, which is a key requirement for some applications. We reported earlier that emulsions could not be made in higher $\mathrm{pH}$ dispersions (such as pH 7 and $\mathrm{pH}$ 10) using the membrane emulsification method, which is a limitation.

We successfully used probe sonication to fabricate ND-stabilized Pickering emulsions using ND dispersions with a wide range of $\mathrm{pH}$ (acidic to alkaline). Optical microscope images of the sonicated emulsion drops are shown in Fig. 11. Oil drop sizes were significantly lower with the probe sonication method in comparison to membrane emulsification. Probe sonication most likely divides the oil phase more finely and imparts kinetic energy to nanoparticles, which promotes their adsorption of particles at the oil/water interface in a short enough time-scale to allow stabilization of the oil droplets. 
The oil droplet size cannot be determined precisely from optical microscopy. In fact, at higher $\mathrm{pH}$ values, the droplets cannot be discerned in the images such as Fig. 11b for emulsions in $\mathrm{pH}$ 7. Instead, DLS was used to characterize the size distribution for emulsions prepared from $\mathrm{pH} 2$ to $\mathrm{pH} 12$. As is shown in Fig. 11c, the size of oil droplets in the emulsion becomes smaller with an increase of the $\mathrm{pH}$ value. For emulsions prepared at $\mathrm{pH} 2$, the surface coverage was estimated (as shown in the Supplementary Materials) to be 20\%. According to other reports on silica stabilized oil-in-water Pickering emulsions, nanoparticle surface coverages can be as low as $5 \%$ in stable emulsions. [64]

Microscope images of ND-stabilized Pickering emulsions prepared in $1 \mathrm{M} \mathrm{NaCl}$ solutions and $1 \mathrm{M} \mathrm{CaCl}_{2}$ solutions are shown in Fig. S12. These emulsion droplets were also small, and their sizes could not be measured because of the quick formation of oil drop clusters.
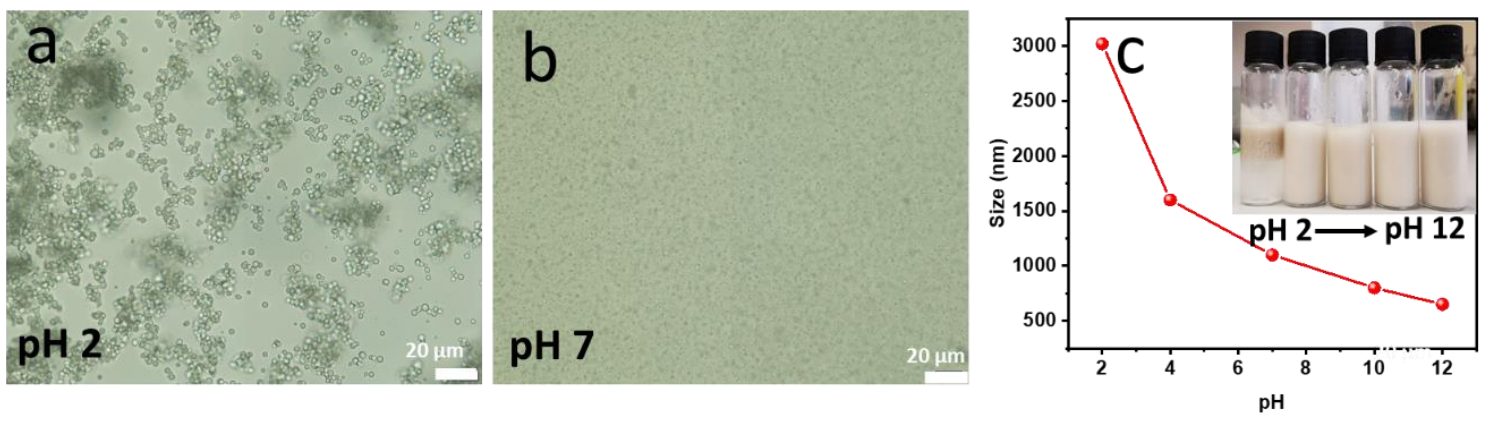

Fig. 11. Optical microscope images of the Pickering emulsions prepared by sonication of ND dispersions with different $\mathrm{pH}$, after ageing for one week, (a) $\mathrm{pH} 2$ and (b) $\mathrm{pH} 7$. The scale bars are $20 \mu \mathrm{m}$. (c) A graph of the volume-average size of emulsion droplets (obtained via DLS) as a function of the $\mathrm{pH}$ of the ND dispersions. The inset shows digital photographs of the emulsions prepared from the ND dispersions ( $\mathrm{pH}$ increasing from left to right from 2 to 12).

\subsubsection{Storage stability against creaming}

Due to the density difference between the oil and water phases, the creaming and phase separation (emulsion phase and aqueous serum phase) of Pickering emulsion appear during long-term storage.[68] For a single oil drop stabilized by nanoparticles in the water phase, the density of the drop system (including particles at the interface and oil), the size of the oil droplets, and the interaction between different oil drops will all influence the value of creaming index over time. The velocity, $v$, for the creaming (or sedimentation) of a single oil drop (with a radius of $r$ ) is given by Stokes' equation: 
$v=\frac{2 g r^{2} \Delta \rho}{9 \eta}$

where $\eta$ is viscosity of the continuous (water) phase. This equation predicts that emulsions prepared by sonication with a higher $\mathrm{pH}$ will cream at a slower rate because of the smaller oil droplet size.

A lower creaming index value and greater storage stability can arise through steric hindrance and electrostatic repulsion that effectively inhibit the aggregation of emulsion droplets.[69] Here, the storage stability of the ND-stabilized Pickering emulsions fabricated by probe sonication was monitored by measurements of the creaming index from visual appearance over $300 \mathrm{~h}$, and is presented in Fig. 12.

The creaming indices for the ND-stabilized Pickering emulsions at $\mathrm{pH} 2$ and in $1 \mathrm{M}$ $\mathrm{NaCl}$ and $\mathrm{CaCl}_{2}$ solutions increased dramatically during the first $50 \mathrm{~h}$. After monitoring for about $100 \mathrm{~h}$, the value tends to be stable for these three groups. The reason for the apparently high increasing rate of the creaming index is probably due to the strong aggregation tendency of ND, which can be observed in Fig. S12, as a result of protonation of carboxylic groups at $\mathrm{pH} 2$ and strong electrostatic shielding in $\mathrm{NaCl}$ and $\mathrm{CaCl}_{2}$ solutions.

Comparing the creaming index values of the different $\mathrm{pH}$ dispersions, the emulsion at $\mathrm{pH} 2$ has a higher increasing rate and a higher stable creaming index value. According to the zeta potential measurements, the ND nanoparticles have a lower electrostatic charge (and hence a weaker repulsion) when in a low $\mathrm{pH}$, leading to a higher creaming index. Emulsions with $\mathrm{pH}$ values of 4, 7, 10, and 12 have a greater stability over the storage time (Fig. 12). Furthermore, there is a decreasing trend of the stability when the $\mathrm{pH}$ value is increased, as can be seen in the creaming index when $\mathrm{pH}$ increases from 4 to 10 . However, the storage stability of emulsions made at $\mathrm{pH} 12$ is extremely high and is even comparable with the emulsion made at $\mathrm{pH} 4$. This finding can be explained by saponification of the sunflower oil in alkaline conditions whereby anionic surfactants are produced to provide additional charge stabilization. 


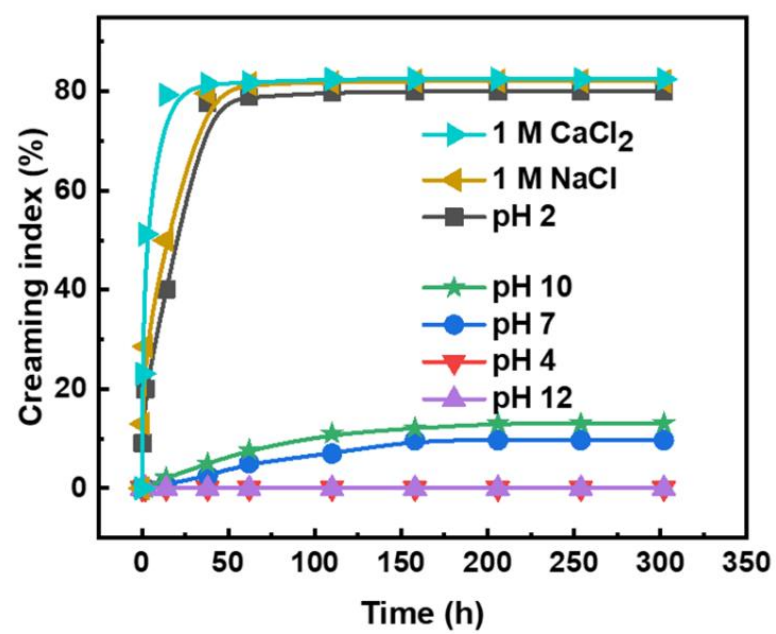

Fig. 12. Effects of $\mathrm{pH}$ and salt on the creaming index of ND-stabilized Pickering emulsions prepared via sonication. A lower creaming index indicates greater stability.

\section{Conclusions}

We have obtained fundamental information about ND in aqueous dispersions and at interfaces with oil, which we exploited successfully to prepare Pickering emulsions. Carboxylated ND in DI-water carry a negative surface charge, which becomes more negative as the $\mathrm{pH}$ increases. Electrostatic repulsions between charged ND particles may act against the adsorption at the oil/water interface. However, the electrolytes contained at low concentrations in buffers screen the surface charge of the ND and promote their adsorption at the interface, assisting in Pickering emulsion stabilization.

Three-phase contact angle analysis showed that ND coatings become more hydrophilic with increasing $\mathrm{pH}$, because of deprotonation of the carboxylic acid groups. Tensiometry confirmed the existence of the ND at the oil/water interface, which is consistent with the threephase contact angle taking values around $90^{\circ}$ and likewise correlates with the emulsion stability. The interfacial tension decreased with increasing ND concentrations, in agreement with previous research on interfacially-active nanoparticles. Moreover, ND coverage was seen to protect the oil drop from saponification in alkaline environments.

This analysis explains why our hypothesis that ND can function as a Pickering stabilizer proved to be true. Indeed, for the first time, monodispersed ND-stabilized Pickering oil-inwater emulsions (with a mean size of about $35 \mu \mathrm{m}$ and $\mathrm{CV} \approx 10 \%$ )) were prepared by membrane emulsification using $0.5 \mathrm{mg} / \mathrm{mL} \mathrm{ND}$ (only 0.05 wt.\%) in a $\mathrm{pH} 4$ buffer solution. Emulsification was achieved with a much lower concentration of nanoparticles than is needed 
when using silica nanoparticles or latex particles.[62] The small size of ND clusters makes them more efficient as emulsifiers.

The emulsions showed long-term stability, as almost no changes of emulsion drop size were found after 12 months of aging or $6 \mathrm{~h}$ of continuous shaking. Moreover, the emulsions showed high stability upon the addition of buffers over a wide range of $\mathrm{pH}$ (acidic to alkaline). Only a minor fraction of droplets was seen, under the optical microscope, to break up upon the addition of $\mathrm{pH} 12$ buffer. This result is attributed to the destabilization of the oil droplets, which was caused by deprotonation of the carboxylated ND and ND aggregation at the oil/water interface (induced by ions, including $\mathrm{Ca}^{2+}$ ). Subsequently, the oil is more exposed to the alkaline water phase, and the saponification of the oil and salting-out follow.

The size of the emulsion droplets prepared via membrane emulsification did not depend on the ND concentration at concentrations of $0.1 \mathrm{mg} / \mathrm{mL}$ and higher. However, at lower ND concentrations, the system was in an "emulsifier poor" region where the size decreased with increasing ND concentration. When the ND concentration is higher than $0.23 \mathrm{mg} / \mathrm{mL}$, we estimate that ND particle clusters can pack together in a monolayer shell around the oil droplet. Higher ND concentrations do not drive the formation of smaller oil droplets, but instead yield ND clusters in solution.

The membrane emulsification method was highly effective in producing Pickering emulsions with a relatively large size $(10 \mathrm{~s}$ of $\mu \mathrm{m})$ and with a narrow size distribution, which is a key requirement for some applications. It was only applicable to Pickering emulsions under acidic conditions ( $\mathrm{pH} 1.5$ and 4). However, membrane emulsification offers good control of droplet size, and it consumes less energy compared to sonication. This emulsification method could also be applied at larger volumes in the future.

In contrast, probe sonication was demonstrated to be a good alternative that facilitates the formation of ND-stabilized Pickering emulsions across a wide $\mathrm{pH}$ range (from $\mathrm{pH} 2$ to $\mathrm{pH}$ 12), achieving oil droplet sizes even smaller than $1 \mu \mathrm{m}$. The long-term storage stability of these smaller-sized emulsions was similar for $\mathrm{pH} 12$ and $\mathrm{pH} 4$ solutions. For ND-stabilized Pickering emulsions prepared at $\mathrm{pH} 2$ and also in $\mathrm{NaCl}$ and $\mathrm{CaCl}_{2}$ concentrated solutions, a high creaming index (poor stability) was found, because of ND aggregation.

This is the first systematic study of carboxylated ND-stabilized Pickering emulsions. With the foundation of fundamental knowledge established here, there is promise for the potential development of future applications. We demonstrated the delivery of a model active ingredient ( $\beta$-carotene) in oil, and propose that other oil-soluble molecules, such as curcumin, 
could be emulsified in the future.[70] Because of the low toxicity[24][25] and biocompatibility of ND, these emulsions hold promise in pharmaceutical and drug delivery applications.[2931] We also envisage the manufacture of ND/polymer nanocomposites[21] by dissolving polymers in a volatile oil phase or by miniemulsion polymerization.

\section{Acknowledgement}

The authors acknowledge the Chinese Scholarship Council (CSC 201906950049) and the Vice-Chancellor's Scholarship Fund for providing a PhD studentship for ZH. This research was supported by the Aragón Regional Government (project E25_20R). We thank Prof. Spencer Taylor (University of Surrey) for advice in pendant drop tensiometry and helpful discussions, Dr. Ian Williams for assistance in construction of the sample cell, and Philipp Moritz (Technical University of Clausthal) for preliminary experiments.

\section{CRediT Author Statement}

Zhiwei Huang: Conceptualization, formal analysis, investigation, methodology, visualization, writing original draft. Izabela Jurewicz: Conceptualization, methodology, supervision, resources, writing - reviewing and editing. Edgar Muñoz: Conceptualization, resources, writing - reviewing and editing. Rosa Garriga: Conceptualization, resources, writing reviewing and editing. Joseph L. Keddie: Conceptualization, methodology, supervision, funding acquisition, writing - reviewing and editing.

\section{References}

[1] W. Ramsden, Separation of solids in the surface-layers of solutions and "suspensions," Proc. R. Soc. London. 72 (1903) 156-164.

[2] S.U. Pickering, CXCVI.-Emulsions, J. Chem. Soc. Trans. 91 (1907) 2001-2021.

[3] J. Wu, G.H. Ma, Recent studies of Pickering emulsions: particles make the difference, Small. 12 (2016) 4633-4648.

[4] J.H. Clint, S.E. Taylor, Particle size and interparticle forces of overbased detergents: A Langmuir trough study, Colloids and Surfaces. 65 (1992) 61-67.

[5] A. Schrade, K. Landfester, U. Ziener, Pickering-type stabilized nanoparticles by heterophase polymerization, Chem. Soc. Rev. 42 (2013) 6823-6839.

[6] Y. Chevalier, M.A. Bolzinger, Emulsions stabilized with solid nanoparticles: Pickering 
emulsions, Colloids Surfaces A Physicochem. Eng. Asp. 439 (2013) 23-34.

[7] M. Rayner, D. Marku, M. Eriksson, M. Sjöö, P. Dejmek, M. Wahlgren, Biomass-based particles for the formulation of Pickering type emulsions in food and topical applications, Colloids Surfaces A Physicochem. Eng. Asp. 458 (2014) 48-62.

[8] J. Marto, A. Ascenso, L.M. Gonçalves, L.F. Gouveia, P. Manteigas, P. Pinto, E. Oliveira, A.J. Almeida, H.M. Ribeiro, Melatonin-based pickering emulsion for skin's photoprotection, Drug Deliv. 23 (2016) 1594-1607.

[9] J. Wang, W.C. Law, L. Chen, D. Chen, C.Y. Tang, Fabrication of monodisperse drugloaded poly(lactic-co-glycolic acid)-chitosan core-shell nanocomposites via pickering emulsion, Compos. Part B Eng. 121 (2017) 99-107.

[10] F. Laredj-Bourezg, M.A. Bolzinger, J. Pelletier, Y. Chevalier, Pickering emulsions stabilized by biodegradable block copolymer micelles for controlled topical drug delivery, Int. J. Pharm. 531 (2017) 134-142.

[11] Y. Yang, Z. Fang, X. Chen, W. Zhang, Y. Xie, Y. Chen, Z. Liu, W. Yuan, An overview of pickering emulsions: Solid-particle materials, classification, morphology, and applications, Front. Pharmacol. 8 (2017) 287.

[12] L. Bai, S. Huan, W. Xiang, O.J. Rojas, Pickering emulsions by combining cellulose nanofibrils and nanocrystals: Phase behavior and depletion stabilization, Green Chem. 20 (2018) 1571-1582.

[13] M. V. Tzoumaki, T. Moschakis, V. Kiosseoglou, C.G. Biliaderis, Oil-in-water emulsions stabilized by chitin nanocrystal particles, Food Hydrocoll. 25 (2011) 15211529.

[14] J. Xiao, Y. Li, Q. Huang, Recent advances on food-grade particles stabilized Pickering emulsions: Fabrication, characterization and research trends, Trends Food Sci. Technol. 55 (2016) 48-60.

[15] J. Marto, A. Ascenso, S. Simoes, A.J. Almeida, H.M. Ribeiro, Pickering emulsions: challenges and opportunities in topical delivery, Expert Opin. Drug Deliv. 13 (2016) 1093-1107.

[16] J. Kim, L.J. Cote, F. Kim, W. Yuan, K.R. Shull, J. Huang, Graphene oxide sheets at interfaces, J. Am. Chem. Soc. 132 (2010) 8180-8186. 
[17] M.J. Large, S.P. Ogilvie, M. Meloni, A. Amorim Graf, G. Fratta, J. Salvage, A.A.K. King, A.B. Dalton, Functional liquid structures by emulsification of graphene and other two-dimensional nanomaterials, Nanoscale. 10 (2018) 1582-1586.

[18] M.A. O’Mara, S.P. Ogilvie, M.J. Large, A. Amorim Graf, A.C. Sehnal, P.J. Lynch, J.P. Salvage, I. Jurewicz, A.A.K. King, A.B. Dalton, Ultrasensitive Strain Gauges Enabled by Graphene-Stabilized Silicone Emulsions, Adv. Funct. Mater. 30 (2020) 2002433.

[19] X. Wang, K. Yu, R. An, L. Han, Y. Zhang, L. Shi, R. Ran, Self-assembling GO/modified HEC hybrid stabilized pickering emulsions and template polymerization for biomedical hydrogels, Carbohydr. Polym. 207 (2019) 694-703.

[20] F. Zhang, L. Liu, X. Tan, X. Sang, J. Zhang, C. Liu, B. Zhang, B. Han, G. Yang, Pickering emulsions stabilized by a metal-organic framework (MOF) and graphene oxide (GO) for producing MOF/GO composites, Soft Matter. 13 (2017) 7365-7370.

[21] E. Bourgeat-Lami, J. Faucheu, A. Noël, Latex routes to graphene-based nanocomposites, Polym. Chem. 6 (2015) 5323-5357.

[22] H. Katepalli, V.T. John, A. Bose, The response of carbon black stabilized oil-in-water emulsions to the addition of surfactant solutions, Langmuir. 29 (2013) 6790-6797.

[23] A. Saha, A. Nikova, P. Venkataraman, V.T. John, A. Bose, Oil emulsification using surface-tunable carbon black particles, ACS Appl. Mater. Interfaces. 5 (2013) 30943100.

[24] K. van der Laan, M. Hasani, T. Zheng, R. Schirhagl, Nanodiamonds for in vivo applications, Small. 14 (2018) 1703838.

[25] V.N. Mochalin, O. Shenderova, D. Ho, Y. Gogotsi, The properties and applications of nanodiamonds, Nat. Nanotechnol. 7 (2012) 11-23.

[26] Y. Zhu, J. Li, W. Li, Y. Zhang, X. Yang, N. Chen, Y. Sun, Y. Zhao, C. Fan, Q. Huang, The biocompatibility of nanodiamonds and their application in drug delivery systems, Theranostics. 2 (2012) 302-312.

[27] R. Garriga, T. Herrero-Continente, M. Palos, V.L. Cebolla, J. Osada, E. Muñoz, M.J. Rodríguez-Yoldi, Toxicity of carbon nanomaterials and their potential application as drug delivery systems: In vitro studies in Caco-2 and MCF-7 cell lines, Nanomaterials. 
$10(2020) 1617$.

[28] M. Ozawa, M. Inaguma, M. Takahashi, F. Kataoka, A. Krüger, E. Osawa, Preparation and behavior of brownish, clear nanodiamond colloids, Adv. Mater. 19 (2007) 12011206.

[29] A. Krueger, New carbon materials: Biological applications of functionalized nanodiamond materials, Chem. Eur. J. 14 (2008) 1382-1390.

[30] M.S. Ali, A.A. Metwally, R.H. Fahmy, R. Osman, Nanodiamonds: Minuscule gems that ferry antineoplastic drugs to resistant tumors, Int. J. Pharm. 558 (2019) 165-176.

[31] A.H. Day, S.J. Adams, L. Gines, O.A. Williams, B.R.G. Johnson, I.A. Fallis, E.J. Loveridge, G.S. Bahra, P.C.F. Oyston, J.M. Herrera, S.J.A. Pope, Synthetic routes, characterization and photophysical properties of luminescent, surface functionalized nanodiamonds, Carbon N. Y. 152 (2019) 335-343.

[32] M. Maas, T. Bollhorst, R.N. Zare, K. Rezwan, Diamondosomes: Submicron colloidosomes with nanodiamond shells, Part. Part. Syst. Charact. 31 (2014) 10671071.

[33] B. V. Farias, D. Brown, A. Hearn, N. Nunn, O. Shenderova, S.A. Khan, Nanodiamond-stabilized Pickering emulsions: Microstructure and rheology, J. Colloid Interface Sci. 580 (2020) 180-191.

[34] J.M. Rosenholm, I.I. Vlasov, S.A. Burikov, T.A. Dolenko, O.A. Shenderova, Nanodiamond-based composite structures for biomedical imaging and drug delivery, J. Nanosci. Nanotechnol. 15 (2015) 959-971.

[35] M. Chen, E.D. Pierstorff, R. Lam, S.Y. Li, H. Huang, E. Osawa, D. Ho, Nanodiamondmediated delivery of water-insoluble therapeutics, ACS Nano. 3 (2009) 2016-2022.

[36] Z. Wang, Z. Tian, Y. Dong, L. Li, L. Tian, Y. Li, B. Yang, Nanodiamond-conjugated transferrin as chemotherapeutic drug delivery, Diam. Relat. Mater. 58 (2015) 84-93.

[37] M.S. Manga, D.W. York, Production of concentrated Pickering emulsions with narrow size distributions using stirred cell membrane emulsification, Langmuir. 33 (2017) 9050-9056.

[38] A. Krueger, D. Lang, Functionality is key: Recent progress in the surface modification 
of nanodiamond, Adv. Funct. Mater. 22 (2012) 890-906.

[39] N.M. Kuznetsov, S.I. Belousov, R.A. Kamyshinsky, A.L. Vasiliev, S.N. Chvalun, E.B. Yudina, A. Ya. Vul, Detonation nanodiamonds dispersed in polydimethylsiloxane as a novel electrorheological fluid: Effect of nanodiamonds surface, Carbon N. Y. 174 (2021) 138-147.

[40] J. Beltz, A. Pfaff, I.M. Abdullahi, A. Cristea, V.N. Mochalin, N. Ercal, Effect of nanodiamond surface chemistry on adsorption and release of tiopronin, Diam. Relat. Mater. 100 (2019) 107590.

[41] A.M. Vervald, E.N. Vervald, S.A. Burikov, S. V Patsaeva, N.A. Kalyagina, N.E. Borisova, I.I. Vlasov, O.A. Shenderova, T.A. Dolenko, Bilayer Adsorption of Lysozyme on Nanodiamonds in Aqueous Suspensions, J. Phys. Chem. C. 124 (2020) $4288-4298$.

[42] G.T. Vladisavljević, Preparation of microemulsions and nanoemulsions by membrane emulsification, Colloids Surfaces A Physicochem. Eng. Asp. 579 (2019) 123709.

[43] N.C. Christov, D.N. Ganchev, N.D. Vassileva, N.D. Denkov, K.D. Danov, P.A. Kralchevsky, Capillary mechanisms in membrane emulsification: oil-in-water emulsions stabilized by Tween 20 and milk proteins, Colloids Surfaces A Physicochem. Eng. Asp. 209 (2002) 83-104.

[44] S.R. Kosvintsev, G. Gasparini, R.G. Holdich, I.W. Cumming, M.T. Stillwell, Liquidliquid membrane dispersion in a stirred cell with and without controlled shear, Ind. Eng. Chem. Res. 44 (2005) 9323-9330.

[45] Ken Kelley, Sample size planning for the coefficient of variation from the accuracy in parameter estimation approach, Behav. Res. Methods. 37 (2007) 755-766.

[46] J.M. Andreas, E.A. Hauser, W.B. Tucker, Boundary tension by pendant drops, J. Phys. Chem. 42 (1938) 1001-1019.

[47] I. Niă, A. Neagu, S. Geacai, Study of the behavior of some vegetable oils during the thermal treatment, Ovidius Univ. Ann. Chem. 21 (2010) 5-8.

[48] E. Keowmaneechai, D.J. McClements, Influence of EDTA and citrate on physicochemical properties of whey protein-stabilized oil-in-water emulsions containing CaCl2, J. Agric. Food Chem. 50 (2002) 7145-7153. 
[49] M.S. Manga, O.J. Cayre, R.A. Williams, S. Biggs, D.W. York, Production of solidstabilised emulsions through rotational membrane emulsification: Influence of particle adsorption kinetics, Soft Matter. 8 (2012) 1532-1538.

[50] A.M. Panich, A.E. Aleksenskii, Deaggregation of diamond nanoparticles studied by NMR, Diam. Relat. Mater. 27-28 (2012) 45-48.

[51] P. Reineck, D.W.M. Lau, E.R. Wilson, N. Nunn, O.A. Shenderova, B.C. Gibson, Visible to near-IR fluorescence from single-digit detonation nanodiamonds: Excitation wavelength and pH dependence, Sci. Rep. 8 (2018) 2478.

[52] E.B. Yudina, A.E. Aleksenskii, I.G. Fomina, A. V. Shvidchenko, D.P. Danilovich, I.L. Eremenko, A.Y. Vul, Interaction of carboxyl groups with rare metal ions on the surface of detonation nanodiamonds, Eur. J. Inorg. Chem. (2019) 4345-4349.

[53] C. Desai, K. Chen, S. Mitra, Aggregation behavior of nanodiamonds and their functionalized analogs in an aqueous environment, Environ. Sci. Process. Impacts. 16 (2014) 518-523.

[54] A.E. Aleksenskiy, E.D. Eydelman, A.Y. Vul, Deagglomeration of detonation nanodiamonds, Nanosci. Nanotechnol. Lett. 3 (2011) 68-74.

[55] R. Aveyard, B.P. Binks, J.H. Clint, Emulsions stabilised solely by colloidal particles, Adv. Colloid Interface Sci. 100-102 (2003) 503-546.

[56] G.D. Beal, Myristic Acid, Org. Synth. 6 (1926) 66.

[57] L.R. Fisher, E.E. Mitchell, N.S. Parker, Interfacial tensions of commercial vegetable oils with water, J. Food Sci. 50 (1985) 1201-1202.

[58] J. Hasnain, Y. Jiang, H. Hou, J. Yan, L. Athanasopoulou, J. Forth, P.D. Ashby, B.A. Helms, T.P. Russell, P.L. Geissler, Spontaneous emulsification induced by nanoparticle surfactants, J. Chem. Phys. 153 (2020) 224705.

[59] L. Ridel, M.A. Bolzinger, N. Gilon-Delepine, P.Y. Dugas, Y. Chevalier, Pickering emulsions stabilized by charged nanoparticles, Soft Matter. 12 (2016) 7564-7576.

[60] B.E. H Lucassen-Reynders, M. van den Tempel, Stabilization of water-in-oil emulsions by solid particles, J. Phys. Chem. 67 (1963) 731-734.

[61] B.P. Binks, S.O. Lumsdon, Stability of oil-in-water emulsions stabilised by silica 
particles, Phys. Chem. Chem. Phys. 1 (1999) 3007-3016.

[62] S. Tcholakova, N.D. Denkov, A. Lips, Comparison of solid particles, globular proteins and surfactants as emulsifiers, Phys. Chem. Chem. Phys. 10 (2008) 1608-1627.

[63] S. Tcholakova, N.D. Denkov, D. Sidzhakova, I.B. Ivanov, B. Campbell, Interrelation between drop size and protein adsorption at various emulsification conditions, Langmuir. 19 (2003) 5640-5649.

[64] E. Vignati, R. Piazza, T.P. Lockhart, Pickering emulsions: Interfacial tension, colloidal layer morphology, and trapped-particle motion, Langmuir. 19 (2003) 6650-6656.

[65] D.E. Tambe, M.M. Sharma, The effect of colloidal particles on fluid-fluid interfacial properties and emulsion stability, Adv. Colloid Interface Sci. 52 (1994) 1-63.

[66] J. Frelichowska, M.A. Bolzinger, Y. Chevalier, Effects of solid particle content on properties of o/w Pickering emulsions, J. Colloid Interface Sci. 351 (2010) 348-356.

[67] D.E. Tambe, M.M. Sharma, Factors controlling the stability of colloid-stabilized emulsions. I. An experimental investigation, J. Colloid Interface Sci. 157 (1993) 244253.

[68] F. Liu, C.H. Tang, Soy glycinin as food-grade Pickering stabilizers: Part. I. Structural characteristics, emulsifying properties and adsorption/arrangement at interface, Food Hydrocoll. 60 (2016) 606-619.

[69] X. Lu, J. Xiao, Q. Huang, Pickering emulsions stabilized by media-milled starch particles, Food Res. Int. 105 (2018) 140-149.

[70] Y. Li, W. Li, W. Bao, B. Liu, D. Li, Y. Jiang, W. Wei, F. Ren, Bioinspired peptosomes with programmed stimuli-responses for sequential drug release and high-performance anticancer therapy, Nanoscale. 9 (2017) 9317-9324. 